\title{
Cardiovascular ephrinB2 function is essential for embryonic angiogenesis
}

\author{
Sebastian S. Gerety ${ }^{1, \dagger}$ and David J. Anderson ${ }^{1,2, *}$ \\ ${ }^{1}$ Division of Biology 216-76, California Institute of Technology, Pasadena, CA 91125, USA \\ ${ }^{2}$ Howard Hughes Medical Institute, California Institute of Technology, Pasadena, CA 91125, USA \\ *Author for correspondence (e-mail: c/o mancusog@cco.caltech.edu) \\ tPresent address: Department of Developmental Neurobiology, NIMR, The Rldgeway, Mill Hill, London NW7 1AA, UK \\ Accepted 19 December 2001
}

\section{SUMMARY}

EphrinB2, a transmembrane ligand of EphB receptor tyrosine kinases, is specifically expressed in arteries. In ephrinB2 mutant embryos, there is a complete arrest of angiogenesis. However, ephrinB2 expression is not restricted to vascular endothelial cells, and it has been proposed that its essential function may be exerted in adjacent mesenchymal cells. We have generated mice in which ephrinB2 is specifically deleted in the endothelium and endocardium of the developing vasculature and heart. We find that such a vascular-specific deletion of ephrinB2

\section{INTRODUCTION}

The development of the embryonic vasculature involves the remodeling of a primitive capillary plexus into a more organized, highly branched vessel network (Risau and Flamme, 1995). The primary vascular plexi are laid down during the process of vasculogenesis, in which endothelial precursors aggregate to form blood islands in the yolk sac and endothelial strands in the embryo proper (Risau and Flamme, 1995). Angiogenesis, the adaptive morphogenetic transformation of these simple networks, results in organized, highly branched, hierarchical networks of large and small vessels. Remodeling during angiogenesis occurs through the sprouting of new branches, the pruning of existing branches, the fusion of neighboring capillaries and the splitting of individual capillaries (intussuception), as well as endothelial proliferation, apoptosis and migration (reviewed by Patan, 2000; Yancopoulos et al., 2000). Integral to this process is the recruitment of supporting pericytes (Schor et al., 1995) and smooth muscle cells (Oh et al., 2000; Yancopoulos et al., 2000; Folkman and D'Amore, 1996).

Angiogenesis involves a complex series of reciprocal interactions between the endothelial cells of the developing blood vessels and neighboring cells. Perivascular mesenchymal cells provide endothelial cells with signals such as vascular endothelial growth factor (VEGF) (Carmeliet et al., 1996; Ferrara et al., 1996) and angiopoietin 1 (Ang1) (Davis et al., 1996; Suri et al., 1996; Sato et al., 1995; Dumont et al., 1994). In turn, endothelial cells send signals of their own, such as platelet-derived growth factor (PDGF) (Hellstrom et al., 1999; Hirschi et al., 1999), transforming growth factor $\beta$ results in angiogenic remodeling defects identical to those seen in the conventional ephrinB2 mutants. These data indicate that ephrinB2 is required specifically in endothelial and endocardial cells for angiogenesis, and that ephrinB2 expression in perivascular mesenchyme is not sufficient to compensate for the loss of ephrinB2 in these vascular cells.

Key words: EphB4, EphrinB2, Angiogenesis, Vasculature, Mouse
(TGFß) (Goumans et al., 1999; Pepper, 1997; Oshima et al., 1996; Dickson et al., 1995) and neuregulin (Kramer et al., 1996; Meyer and Birchmeier, 1995; Marchionni et al., 1993), to surrounding support cells (reviewed by Flamme et al., 1997; Hanahan, 1997). Endothelial cells must also interact with one another, coordinating vessel integrity, identity, growth and remodeling via such molecules as Delta-4 (Krebs et al., 2000; Shutter et al., 2000), integrin $a_{\mathrm{v}} \mathrm{b}_{3}$ (Friedlander et al., 1995; Brooks et al., 1994) and VE-cadherin (Gory-Faure et al., 1999; Breier et al., 1996). Therefore, both endothelial-support cell and inter-endothelial communication are required for proper vessel assembly (Gale and Yancopoulos, 1999; Hanahan, 1997; Folkman and D'Amore, 1996; Risau and Flamme, 1995).

EPH receptor tyrosine kinases and their transmembrane ligands, the ephrins (Wilkinson, 2000), have recently been shown to be expressed in and around the developing circulatory system (reviewed by Adams and Klein, 2000). Several studies have implicated ephrin signaling in endothelial cell behavior and angiogenesis (Adams et al., 2001; Helbling et al., 2000; Adams et al., 1999; Gerety et al., 1999; Stein et al., 1998; Wang et al., 1998; Daniel et al., 1996; Stein et al., 1996). EphrinB2 (Efnb2 - Mouse Genome Informatics) is specifically expressed in arterial endothelial cells, and ephrinB2 homozygous mutant mice die at E9.5 with severe cardiovascular defects (Adams et al., 1999; Wang et al., 1998). To date, ephrinB2 is the only ephrin ligand whose knockout shows an angiogenic phenotype (Adams et al., 1999). Deletion of the ephrinB2 cytoplasmic domain yields an identical vascular phenotype, consistent with the notion that this transmembrane ligand functions in reverse signaling (Adams et al., 2001).

Initial studies suggested that the main ligand function of 
ephrinB2 is exerted in the arterial endothelium, where it mediates signaling to veins via EphB4 (Ephb4 - Mouse Genome Informatics), a receptor more abundantly expressed on venous endothelial cells (Gerety et al., 1999; Wang et al., 1998). Consistent with this notion, Ephb4 mutant mice show angiogenic defects similar or identical to those in ephrinB2-/mice (Gerety et al., 1999). However, in contrast to Ephb4, which is restricted to the cardiovascular system, expression of ephrinB2 is not restricted to endothelial cells, but is also found in mesenchymal cells, pericytes and vascular smooth muscle cells surrounding sites of active angiogenesis (Gale et al., 2001; Shin et al., 2001; Adams et al., 1999; Wang et al., 1998). These observations suggested that ephrinB2 might mediate support cell to endothelial cell communication, as well as interendothelial interactions (Adams et al., 1999; Gale and Yancopoulos, 1999; Gerety et al., 1999). Consistent with this, recent studies in mouse (Adams et al., 1999) and Хеnopus (Helbling et al., 2000) have attributed a role to mesenchymederived ephrinB2 signals in restricting blood vessel growth to the intersomitic space. In these experiments, however, ephrin signaling was disrupted throughout the embryo, obscuring its essential site of action.

We were interested in determining whether endothelial ephrinB2 expression is essential for angiogenesis, or if ephrinB2 derived from perivascular mesenchyme is sufficient to drive vascular remodeling. We therefore constructed a conditional allele of ephrinB2 that can be excised by the expression of Cre recombinase (Cre) in a tissue of interest (Nagy, 2000; Orban et al., 1992). Endothelial-specific deletion was accomplished by the use of a transgenic Tie2-Cre mouse line that expresses Cre in endothelial cells of the embryo (Kisanuki et al., 2001). This endothelial specific knockout of ephrinB2 leads to angiogenic remodeling and cardiac defects that are indistinguishable from those of the conventional ephrinB2 knockout (Wang et al., 1998). These data demonstrate that ephrinB2 is absolutely required in the endothelial and endocardial cells of the developing mouse embryo for proper cardiovascular development of both arteries and veins. In all cases examined, ephrinB2 expression in adjacent mesenchymal tissue was not sufficient to compensate for the loss of endothelial expression in neighboring vessels.

\section{MATERIALS AND METHODS}

\section{Generation of a floxed ephrinB2 allele}

Genomic clones for the ephrinB2 locus were previously isolated (Wang et al., 1998). A double-stranded oligonucleotide containing the 34 bp loxP site sequence and a 3' HindIII restriction site was inserted into an EagI restriction site at position $-45 \mathrm{bp}$ in the $5^{\prime}$ UTR of an ephrinB2 genomic clone that included the first coding exon. From this modified clone an EagI-EcoRI restriction fragment, which encompassed the sequence from the loxP site through the end of coding exon I, was ligated to a $2.8 \mathrm{~kb} \mathrm{XbaI}$-EagI genomic fragment used as the left targeting arm. A 100 bp EcoRI-XbaI genomic fragment starting at the end of exon I was cloned downstream of the left targeting arm, thereby restoring the complete genomic sequence of this locus. For construction of the right targeting arm, a $5.6 \mathrm{~kb} \mathrm{XbaI-}$ Asp 718 genomic fragment starting $100 \mathrm{bp}$ downstream of first coding exon was cloned in multiple steps downstream of a loxP site-flanked $P G K$-neomycin gene (Floxed PGKneo, a generous gift from J. Yoon and B. Wold) derived from pPNT (Tybulewicz et al., 1991). This
PGKneo and right arm fragment was then joined to the left arm construct. The resulting targeting construct thus contained 3 loxP sites (Fig. 1A, 'Targeting vector' triangles). Cre recombinase mediated deletion between the first and second sites results in loss of the ephrinB2 first exon coding region, while deletion between the second and third loxP sites results in deletion of the PGKneo cassette.

Electroporation and selection of AB-1 ES cells (strain $129 \mathrm{SvJ}$ ) were performed essentially as described (Ma et al., 1998), with the exception that FIAU selection was omitted. ES cell targeting efficiency via G418 selection was one out of 12 clones. Homologous recombination of the targeted ephrinB2 locus in ES cells was confirmed by HindIII restriction digest of genomic DNA and Southern blotting. A $1 \mathrm{~kb}$ HindIII-XbaI genomic fragment upstream of the left arm was used as a southern probe (Fig. 1A, 'Probe A') to distinguish the wild-type $(6 \mathrm{~kb})$ or targeted $(4 \mathrm{~kb})$ ephrinB2 locus (Fig. 1B).

To remove the Floxed PGKneo selection cassette, we used transient expression of Cre recombinase. Uncut pBS185 plasmid (Invitrogen) containing CMV-driven Cre recombinase expression was electroporated into homologously recombinant ES cells, and the cells were plated at high density. After 48 hours of growth, the cells were trypsinized and replated at low density. Between 10 and 14 days of growth, individual colonies were picked and replated into 96-well plates. Southern blot analyses of genomic DNA isolated from plate replicates identified ES clones that had undergone deletion of the PGKneo cassette but retained an intact exon I (Fig. 1A, 'Floxed locus'; Fig. 1C, 'Neo deleted'). Genomic DNA was cut with HindIII, and a $1.2 \mathrm{~kb}$ EcoRI-HindIII genomic fragment was used as a Southern probe (Fig. 1A, 'Probe B'). Wild-type, exon 1-deleted and fully deleted loci were indistinguishable using this Southern blot strategy, as they all generate a band of approximately 6kb (Fig. 1C, 'Wildtype'). Blastocyst injection of floxed ephrinB2 ES cells were performed essentially as described (Ma et al., 1998). Germline chimeras were crossed onto a pure C57/B16 background and all subsequent breeding was done in a C57/B16 background.

\section{Genotyping}

PCR genotyping for the conditional ephrinB2 allele (floxed allele) was performed with a $5^{\prime}$ primer specific for the $5^{\prime}$ loxP site insertion, 5'-AAGTTATAAGCTTCAACGCGTCC-3' (TF3), and a 3' primer in the genomic region downstream of exon 1, 5'-GAGCCCCAGGTTCTAGAATAACTTCG-3' (RF1) (product size of 320 bp). Genotyping of the ephrinB2-lacZ allele was carried out with the following lacZ-specific primer pair: 5'-CGCCCGTTGCACCACAGATG-3' (UX-161) and 5'-CCAGCTGGCGTAATAGCGAAG-3' (UX-160G) (product size of 370 bp). The Tie2-Cre transgene was detected by allele specific primers, with a $5^{\prime}$ primer in the Tie2 promoter, 5'-GGGAAGTCGCAAAGTTGTGAGTT-3' (Tie2T5F1) and a $3^{\prime}$ primer in the Cre gene, 5'-CTAGAGCCTGTTTTGCACGTTC-3' (Cre2) (product size of $490 \mathrm{bp}$ ). The wild-type ephrinB2 locus was detected with a $5^{\prime}$ primer that includes sequence flanking the inserted $5^{\prime}$ loxP site, and a $3^{\prime}$ primer downstream of the first exon, 5'-GCTGCCCGCGGCCGGTCCCAACG-3' (BrgF1) and 5'-CCGTTAGTGGCAACGTCCTCCGTCCTCG-3' (HL-I-R2h) (product size of 580bp). Conditional knockout mice were identified by the presence of loxP-allele specific, lacZ allele specific and Tie2-Cre specific PCR products. Homozygous ephrinB2-lacZ embryos were identified by the presence of lacZspecific PCR products and the absence of wild-type ephrinB2-specific PCR products (in duplicate). Homozygous ephrinB2-loxP mice were identified by the presence of loxP-allele specific PCR products and the absence of wild-type ephrinB2-specific PCR products. In all embryos, a small amount of tissue was collected from the tail region for genomic DNA isolation and genotyping. To demonstrate deletion of ephrinB2-loxP exon I in vivo, the following primers were used to distinguish intact (636 bp) and deleted (309 bp) ephrinB2-loxP alleles: 5'-CGGCCGGTCCATAACTTCGTATAGCA-3' (HLF1) and 5'-CCGTTAGTGGCAACGTCCTCCGTCCTCG-3' (HL-I-R2h). 
To generate conditionally deleted ephrinB2 embryos, we first generated mice heterozygous for both the ephrinB2-lacZ allele and the Tie2-Cre transgene (ephrinB2 $2^{l a c Z /+} ;$ Tie $\left.2-C r e^{+}\right)$. These mice were then crossed to ephrinB2-loxP (ephrinB2 $2^{\text {loxP/+}}$ ) heterozygous (or ephrinB2loxP/loxP homozygous) mice. EphrinB2 conventional knockouts were generated by intercross of ephrinB2lacz/+ heterozygotes (Wang et al., 1998). For vascular-specific Cre Recombinase expression, we used the Tie2-Cre transgenic mouse (Kisanuki et al., 2001). The Tie2-Cre expression pattern was examined by crossing Tie2-Cre mice to the R26R Rosa lacZ reporter mice (Soriano, 1999). Embryos were collected at E8.25-E9.5 and processed as described below by X-gal development or immunofluorescent double-labeling.

\section{lacZ and immunohistochemical staining}

To examine lac $Z$ expression, mouse embryos were dissected between
E8.25 and E9.5, fixed in $0.25 \%$ glutaraldehyde/PBS for 5 minutes, rinsed twice with PBS, and stained overnight at $37^{\circ} \mathrm{C}$ in X-Gal buffer $[1.3 \mathrm{mg} / \mathrm{ml}$ potassium ferrocyanide, $1 \mathrm{mg} / \mathrm{ml}$ potassium ferricyanide, $0.2 \%$ Triton $\mathrm{X}-100,1 \mathrm{mM} \mathrm{MgCl} 2$ and $1 \mathrm{mg} / \mathrm{ml} \mathrm{X-Gal} \mathrm{in} \mathrm{phosphate-}$ buffered saline (PBS, pH 7.2)]. For antibody staining, embryos were first fixed overnight in $4 \%$ paraformaldehyde/PBS at $4{ }^{\circ} \mathrm{C}$. For section staining, embryos were embedded in $15 \%$ sucrose and $7.5 \%$ gelatin in PBS, and $15 \mu \mathrm{m}$ sections were collected on a cryostat. Wholemount staining procedures with anti-PECAM1 antibody (clone MEC 13.3, Pharmingen, $1: 200$ overnight at $4^{\circ} \mathrm{C}$ ) and anti- $\beta$-galactosidase antibody (3-prime 5-prime, 1:1000, overnight at $4^{\circ} \mathrm{C}$ ) were essentially as described (Wang et al., 1998). Either HRP-conjugated secondary antibodies (Jackson, 1:200, overnight at $4^{\circ} \mathrm{C}$ ) or secondary antibodies conjugated to FITC or Alexa-568 (Jackson, 1:200, and Molecular Probes 1:250, 1 hour at room temperature) were used for whole-mount staining. For immunofluorescent detection on sections, secondary

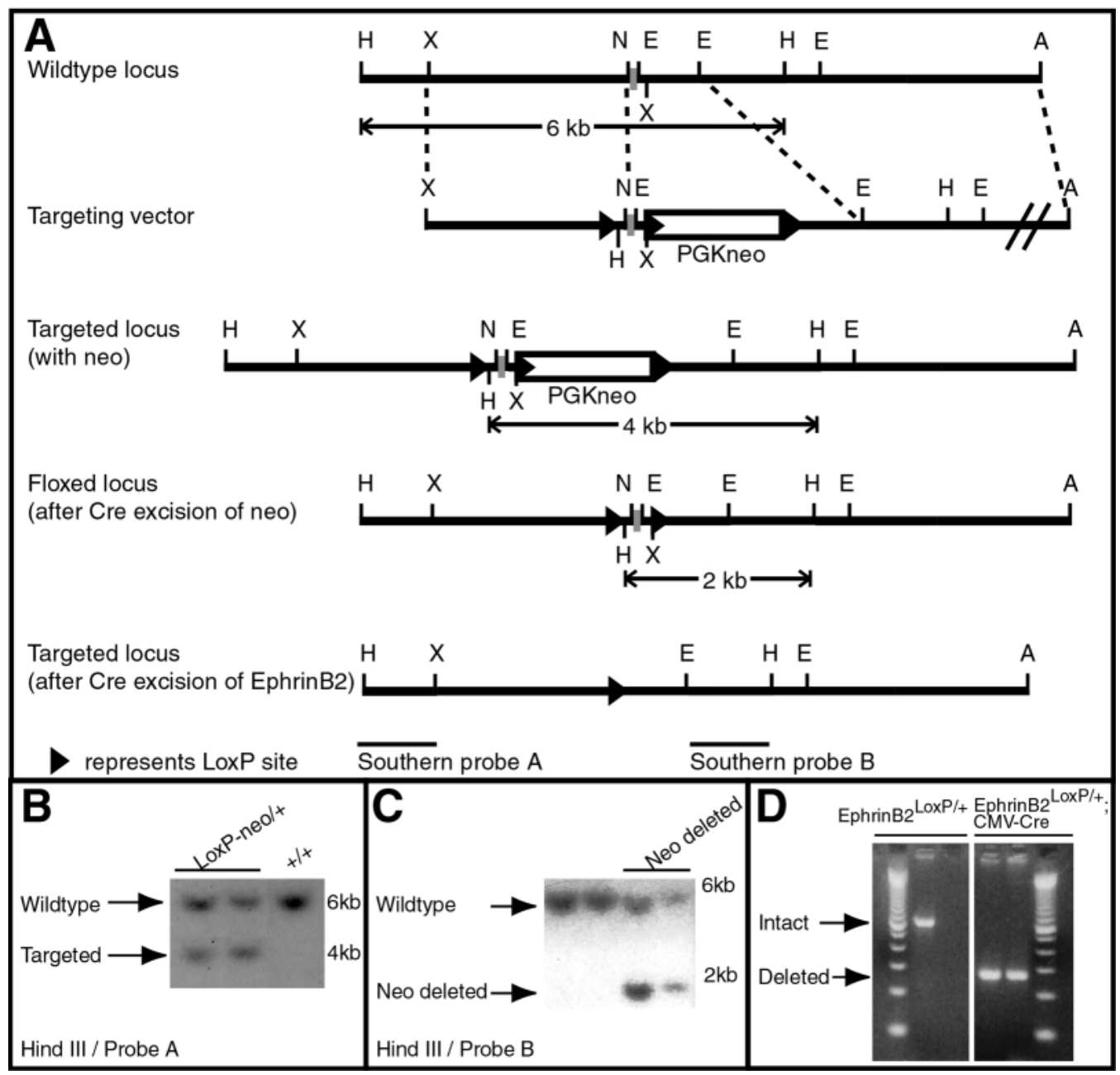

Fig. 1. Generation of the Floxed ephrinB2 locus. (A) Restriction maps of the wild-type ephrinB2 locus, the targeting vector, the initial targeted locus, floxed locus after neo deletion and targeted locus after complete deletion. The targeting vector contains loxP sites (arrowheads) flanking the first coding exon (gray bar). It also contains a floxed PGK-neomycin ('PGKneo') selection cassette that was subsequently removed by transient Cre expression to avoid disturbing normal ephrinB2 transcription (see C). (B) Confirmation of homologous recombination of the targeting vector by Southern blotting. The ES cell genomic DNA has been digested with HindIII, and hybridized with Southern probe A (see A). Wild-type $(6 \mathrm{~kb})$ and targeted (4 kb) loci differ by a HindIII site flanking the $5^{\prime}$ loxP site (see A). (C) Identification of ES cells that have undergone PGKneo cassette deletion (see A) after transient Cre recombinase expression. Genomic DNA was digested with HindIII, and hybridized with southern probe B (see A). 'Neo deleted' indicates loss of PGKneo cassette with retention of the first exon. Deletion of the entire region or deletion of the floxed exon are not distinguishable from wild type in this Southern blot. (D) Confirmation of ephrinB2 exon 1 deletion in mice. Progeny of an ephrinB2 $2^{l o x P /+} \mathrm{X} C M V$-Cre cross show intact (long) or deleted (short) PCR products with primers specific for the loxP allele. 
antibodies conjugated to FITC or Alexa-568 (Jackson, 1:200, and Molecular Probes 1:250) were applied for 1 hour at room temperature. For whole-mount immunofluorescent staining, embryos were cleared in Vectorshield (Molecular Probes) for 20 minutes subsequent to the final antibody wash, then mounted on a slide whose coverslip was elevated by a bridge of two coverslips on each side. This enabled us to avoid crushing the embryos. All confocal microscopy was carried out on a Leica SP confocal (Leica). All brightfield images were captured using an Axiocam CCD camera (Zeiss).

\section{In situ hybridization}

In situ hybridization was carried out essentially as described (Wang et al., 1998; Birren et al., 1993). E9 embryos were cryosectioned at $15 \mu \mathrm{m}$, and adjacent sections were hybridized with RNA probes against the ephrinB2 EC domain (Wang et al., 1998) and Flk1 (KdrMouse Genome Informatics; a generous gift from T. Sato).

\section{RESULTS}

\section{Generation of a conditional ephrinB2 allele}

To study the role of ephrinB2 specifically in the vasculature, we generated a loxP flanked (floxed) ephrinB2 allele. A targeting construct was created with one loxP site inserted into the 5' UTR at $-45 \mathrm{bp}$, and a second site inserted $100 \mathrm{bp}$ downstream of exon I as part of a loxP flanked neomycin resistance cassette (floxed PGKneo, Fig. 1A, 'PGKneo'). This arrangement placed loxP sites flanking exon I, which encodes the ephrinB2 signal peptide, followed by the neo ${ }^{r}$ cassette. Homologous recombinant ES cells were identified by G418 selection and southern analysis (Fig. 1B, 'loxP-neo/+'). The floxed neo cassette was then deleted by transient $\mathrm{Cre}$ expression in ES cells. ES cells with only the neo cassette deleted, and an intact loxP-flanked exon I (Fig. 1A, 'Floxed locus'), were identified by Southern analysis (Fig. 1C), and used to generate chimeric mice. Subsequent intercrossing of $F_{1}$ ephrinB2 $2^{\text {loxP/+ }}$ mice generated homozygous ephrinB2 $2^{\text {lox } P / l o x P}$ mice at expected Mendelian ratios. No obvious detriment to the development and reproductive capacity of the mice carrying two floxed alleles was observed. This suggests that the genomic alteration introduced had no measurable effect on ephrinB2 expression or function.

To verify that the floxed ephrinB2 allele was able to undergo Cre-mediated deletion, ephrinB $2^{l o x P /+}$ mice were crossed to a $C M V$-Cre mouse, in which Cre is expressed in all cells of the early embryo (Zinyk et al., 1998). Embryos that inherited both the ephrinB2 $2^{\text {loxP }}$ allele and the $C M V$-Cre transgene show deletion of the loxP allele by PCR analysis (Fig. 1D, right panel, lower band, 'deleted'). Embryos that inherited the ephrinB2 $2^{\text {loxP }}$ allele but no Cre transgene showed no deletion (Fig. 1D, left panel, upper band, 'intact'). Sequencing of these PCR products confirmed the deletion event (data not shown). Deletion of ephrinB2 exon I by Cre recombinase removes the signal peptide, creating a null allele similar in structure to the original conventional ephrinB2 knockout allele (Wang et al., 1998), but with no lacZ marker included.

\section{Embryonic endothelial-specific Cre expression}

To knock out ephrinB2 specifically in endothelial cells, we used an endothelial-specific $\mathrm{Cre}$-expressing transgenic mouse line, Tie2-Cre (Kisanuki et al., 2001). Tie2, a pan-endothelial receptor tyrosine kinase, is expressed from the earliest timepoints of vascular development (Dumont et al., 1995; Dumont et al., 1992). The Tie2 promoter/enhancer is well characterized and has been shown to drive specifically transcription in the majority of embryonic endothelial cells (Schlaeger et al., 1995; Schlaeger et al., 1997).

ephrinB2 expression in the vasculature is first seen around E8.25, immediately after the formation of the primary vascular plexus (Wang et al., 1998). Homozygous ephrinB2 lacZ/lacZ mutants first exhibit cardiovascular defects around E9 (Wang et al., 1998). These two timepoints define the interval during which ephrinB2 function is first required in the vasculature. To verify that the Tie2-Cre transgene is expressed during this interval, we crossed Tie2-Cre ${ }^{+}$mice to the Rosa26 reporter (R26R) strain (Soriano, 1999). In the R26R reporter mice, a floxed transcriptional/translational stop cassette (floxed STOP) (Lakso et al., 1992) is present between the ubiquitously expressing Rosa26 promoter and the lacZ gene. Any cell expressing Cre will excise the floxed STOP, allowing lacZ expression in that cell and all its progeny (Nagy, 2000). Using
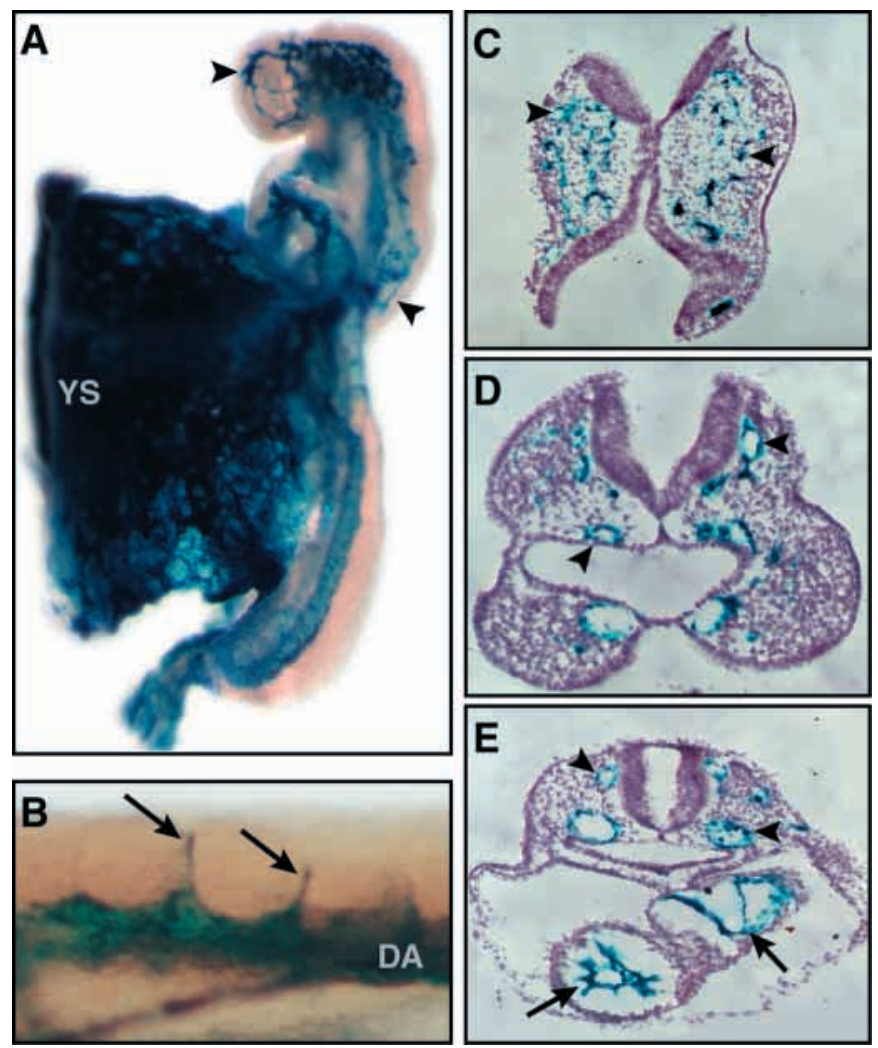

Fig. 2. Tie2-Cre activity in early embryogenesis is restricted to the vasculature. (A-E) Widespread vascular activity of Tie2-Cre in the progeny of a Tie2-Cre X R26R lacZ reporter cross at E8.25, revealed by X-gal staining (blue color). (A) The highly vascularized yolk sac (YS) shows intense Tie2-Cre activity. The primitive vasculature throughout the embryo proper (arrowheads) also shows Tie2-Cre activity. (B) Close-up photograph of intersomitic sprouts (arrows) from the dorsal aorta (DA) of a similar embryo to (A) shows Tie2Cre activity in vessels undergoing angiogenic sprouting. (C-E) Sections of littermates of A, showing Tie2-Cre activity in vessels (arrowheads) of the head (C), hindbrain (D) and trunk (E). The endocardial lining of the heart is also positive (E, arrows), as expected (Kisanuki et al., 2000). Sections were counterstained with Hematoxylin. 
this reporter line, we confirmed that Tie2-Cre is active throughout the vasculature as early as E8.25 (Fig. 2). At this stage, the yolk sac, a highly vascularized extra-embryonic tissue, shows widespread Tie2-Cre activity (Fig. 2A 'YS'). The primitive vasculature of the embryo proper also shows Tie2Cre activity (Fig. 2A, arrowheads) throughout the vessels of the head, heart region and trunk (Fig. 2C-E, respectively, arrowheads). The endothelial lining of the heart, the endocardium, is also positive, as expected (Fig. 2E, arrows) (Kisanuki et al., 2001; Schlaeger et al., 1997). As ephrinB2 activity is thought to play a role in angiogenic sprouting (Adams et al., 1999), we wanted to confirm that Tie2-Cre was active in endothelial sprouts. Intersomitic vessels derived from vascular sprouts of the dorsal aorta showed clear Tie2-Cre activity (Fig. 2B, arrows, 'DA'). Thus, Tie2-Cre is specifically expressed in the endothelium, including angiogenic sprouts, from a timepoint early enough to delete ephrinB2 when its angiogenic function is first required (Adams et al., 1999; Wang et al., 1998).

\section{Vascular-specific deletion of ephrinB2 results in growth arrest}

In order to knock out ephrinB2 in the vasculature, we generated mice heterozygous for both the conventional, lacZ-marked ephrinB2 allele (Wang et al., 1998) and the Tie2-Cre transgene (ephrinB2 $2^{\text {lacZl+}} ;$ Tie2-Cre ${ }^{+}$), and crossed them to ephrinB2loxP/+ (or ephrinB2loxP/loxP) mice. We collected embryos from this cross at E9.5 and visualized the vasculature by whole-mount antibody staining for PECAM1, a pan-endothelial marker (Fig. 3). We observed a dramatic underdevelopment of ephrinB2 ${ }^{\text {lacZ/loxP }}$;ie2-Cre ${ }^{+}$embryos (Fig. 3C) compared with wild-type littermates (Fig. 3A):

they were smaller and appeared developmentally less advanced. Their hearts were swollen, but were still beating. Blood was occasionally seen flowing through the aortic arches, anterior cardinal veins (ACVs) and dorsal aorta. The vasculature of conditional knockouts was disorganized and less intricately developed than that of wild-type littermates, or littermates that lack the Tie2-Cre transgene or one of the targeted ephrinB2 alleles (Fig. 3DF). A conventional ephrinB2 mutant was collected and stained side-by-side with

Fig. 3. Gross morphology of conditional ephrinB2 knockout embryos and littermates. Comparison of embryos from an ephrinB2 $2^{\text {lacZl++} ; \text { Tie2-Cre }}{ }^{+} \mathrm{X}$ ephrinB2 $2^{\text {loxP/+ }}$ cross (A,C-F), and from an ephrinB2 ${ }^{\text {lacZl+ }}$ intercross (B) by anti-PECAM1 staining at E9.5. The conditional ephrinB2 knockout embryo $(C)$ is growth retarded compared with its wild-type littermates (A) and littermates that lack either the Tie2-Cre allele or one of the targeted ephrinB2 alleles (D-F). An ephrinB2-lacZ homozygous embryo (B) shows developmental arrest similar to the conditional knockout embryo (compare with C). this litter for comparison (Fig. 3B). The vascular-specific knockout (ephrinB2 lacZ/loxP;Tie2-Cre ${ }^{+}$) embryos appeared similar to the conventional ephrinB2 lacZ/lacZ mutants in their reduced size, underdevelopment and vascular disorganization (compare Fig. 3C with 3B). Conditional and conventional knockout embryos were recovered at expected Mendelian ratios at E9.5 ( 1 in 3.9 and 1 in 3.8 respectively, $n=113$ and $n=42$ ). $100 \%$ of conditional mutants recovered at this stage show growth arrest and vascular defects of the yolk sac, embryo proper and heart $(n=29)$.

\section{EphrinB2 is required in endothelial cells for proper peripheral angiogenesis}

Yolk sac

A prominent site of angiogenesis in the early embryo is the yolk sac, where a primitive vascular plexus of small diameter capillaries is assembled by E8.5. This plexus rapidly remodels into a complex, hierarchically branched network. In the yolk sac, ephrinB2 expression is restricted to the endothelium of the arteries (Wang et al., 1998) and is required for angiogenic remodeling of the primary yolk sac plexus (Adams et al., 1999; Wang et al., 1998). In situ hybridization of sectioned yolk sac from E9 embryos with RNA probes to ephrinB2 and Flk1 confirmed that expression of ephrinB2 was restricted to the endothelial, Flkl positive cells (compare Fig. 4A with D). As expected, therefore, in both the conditional and conventional knockouts, ephrinB2 expression is absent from the yolk sac (Fig. 4B,C versus A).

The restriction of ephrinB2 expression in yolk sac to the endothelium suggested that the phenotype of the endothelial specific knockout in this tissue should be identical to that seen
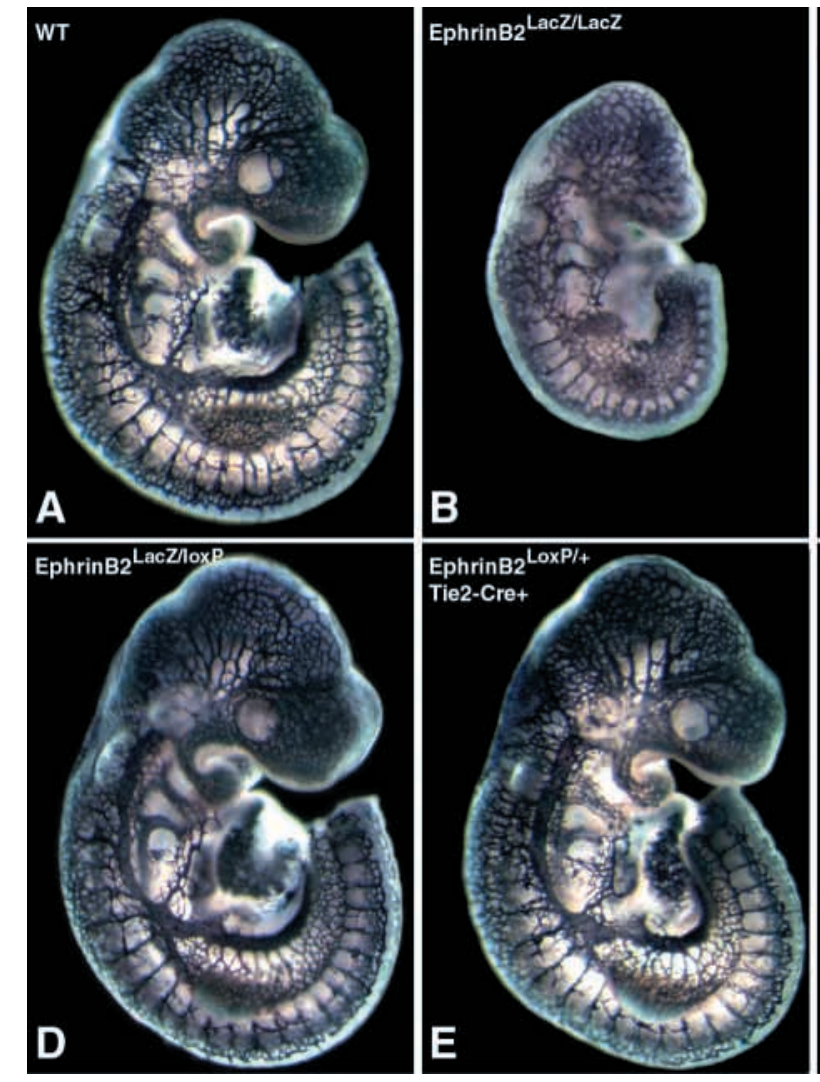

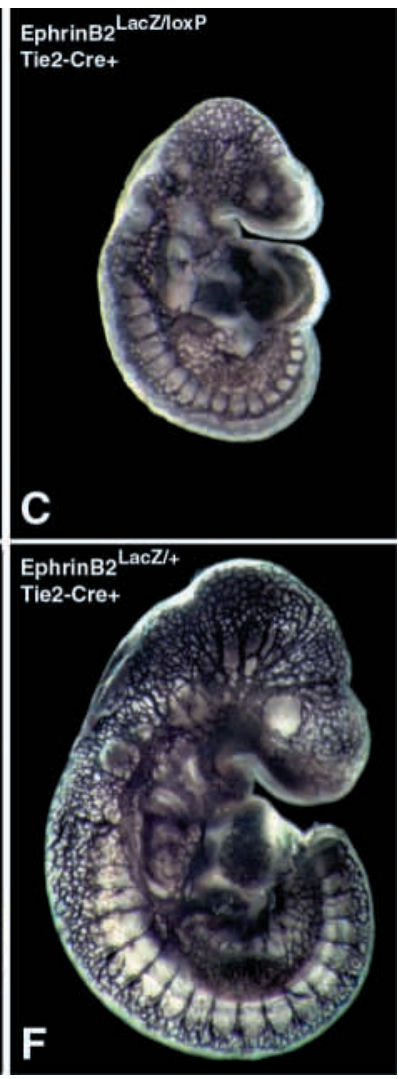



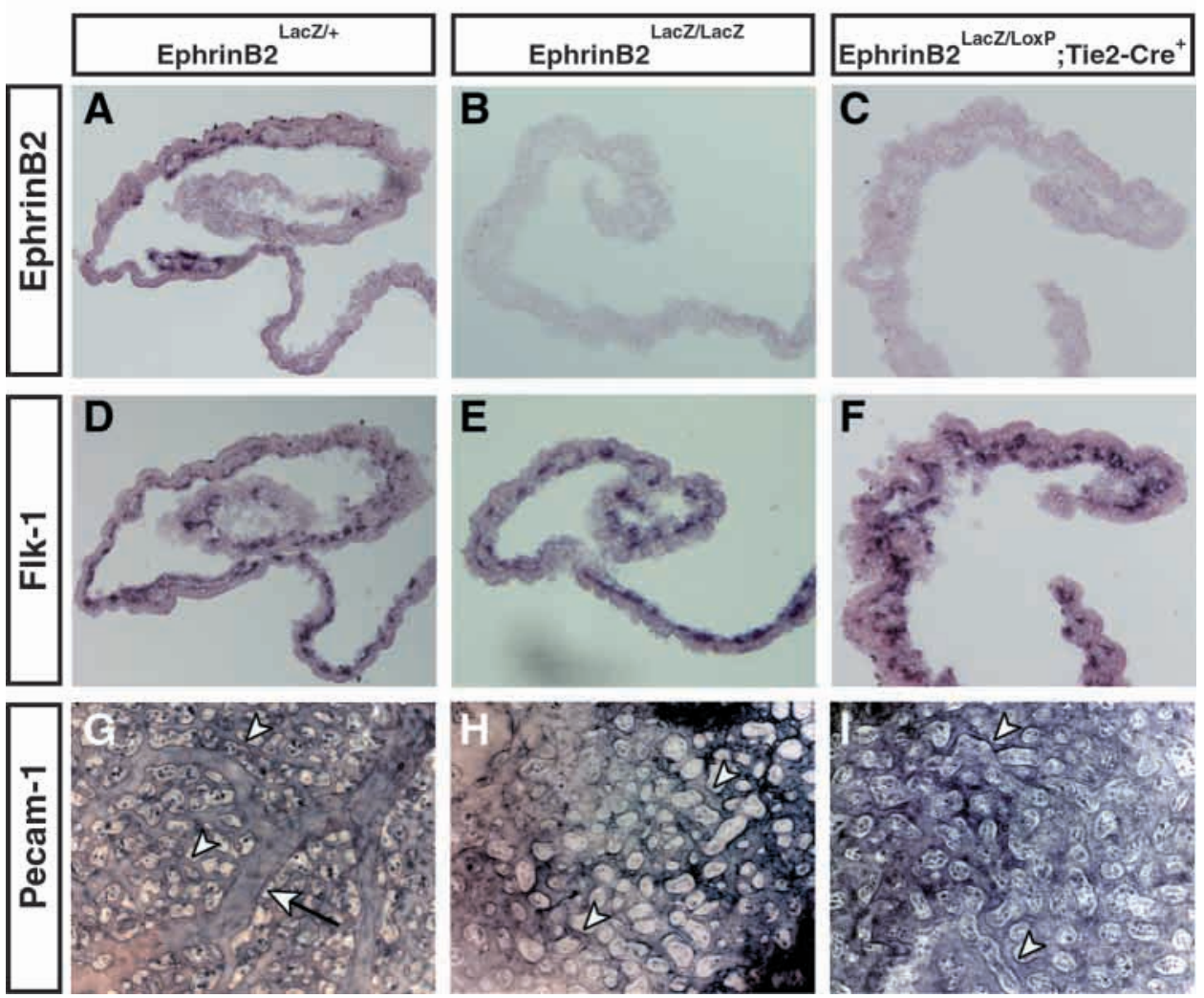

Fig. 4. Yolk sac angiogenesis is defective in conditional ephrinB2 knockout embryos. (A-F) Restriction of ephrinB2 mRNA expression to endothelial cells of the E9 yolk sac is revealed by in situ hybridization with ephrinB2 (A-C) and Flk1 (an endothelial-specific marker, D-F) RNA probes on sections of ephrinB2 $2^{\text {lac Z/+ }}$ control (A,D) ephrinB2 $2^{\text {lacZllacZ }}(\mathrm{B}, \mathrm{E})$ and conditional ephrinB2 knockout $(\mathrm{C}, \mathrm{F})$ yolk sacs at E9. EphrinB2 mRNA in controls is expressed in Flk1-positive endothelial cells (A versus D), and is lost in both conventional (B) and conditional (C) ephrinB2 mutants. (G-I) Identical defects in yolk sac vessel remodeling are seen in ephrinB2 lacZllacZ $(\mathrm{H})$ and conditional ephrinB2 (I) knockout embryos compared with ephrinB2 $2^{\text {lacZl+ }}$ controls $(\mathrm{G})$ are revealed by whole-mount antiPECAM1 staining of E9.5 yolk sacs. The large (arrow) and small (arrowheads) branches in control yolk sacs $(G)$ are instead a plexus of equally sized capillaries (arrowheads) in both mutants $(\mathrm{H}, \mathrm{I})$. in the conventional ephrinB2 knockout. Examination of the yolk sac vasculature of endothelial-specific ephrinB2 knockout embryos (ephrinB2 ${ }^{\text {lacZlloxP }}$; Tie2-Cre ${ }^{+}$) at E9.5 confirmed this, revealing that the failure of arterial and venous angiogenesis identical to that seen in the ephrinB2 $2^{\text {lacZllac } Z}$ homozygous embryos (Fig. 4I versus 4H, and data not shown). The yolk sac vasculature in the conditional knockout was a homogeneous capillary bed, suggesting an arrest in development of arteries and veins at the primary plexus stage. This is in stark contrast to the yolk sac vasculature of littermates, where extensive remodeling of vessels is seen by this age (compare Fig. 4G with I).

\section{EphrinB2 expressed in arteries is required for remodeling of the anterior cardinal vein}

The anterior cardinal veins are the main vessels that transport blood from the head back through the sinus venosus to the heart. These lateral vessels appear around E8.5, after the formation of the dorsal aorta. Each ACV arises initially from the fusion of multiple small vessels present in the lateral mesenchyme of the hindbrain and head (Coffin and Poole, 1988). The early, small diameter vessels that will give rise to the ACVs express EphB4 receptor (Gerety et al., 1999). EphrinB2 is expressed extensively in the hindbrain mesenchyme surrounding the developing $\mathrm{ACV}$, as well as in neighboring neuroepithelium (Fig. 5A-C, red channel, black and white arrowheads, respectively) (Wang et al., 1998). Both ephrinB2 $2^{\text {lacZ }}$ and Ephb4lacZ homozygous embryos show a failure of ACV assembly, resulting in a plexus of disorganized small-diameter vessels (Fig. 5N) (Adams et al., 1999; Gerety et al., 1999). This angiogenic remodeling defect, in a place where no arteriovenous (AV) interface is apparent at E9.5, suggested that ephrinB2 from perivascular mesenchymal cells might signal to EphB4-expressing vessels (Gerety et al., 1999). Double-labeling of E9.5 embryos from a Tie2-Cre X R26R lacZ reporter cross with anti-PECAM1 and anti- $\beta$-Gal confirmed that Tie2-Cre is active only in the endothelium of the hindbrain (Fig. 5D-F, green and red channels, respectively, arrows). We confirmed vessel-specific deletion by in situ hybridization on conventionally and conditionally knocked-out embryos and littermates (Fig. 5G-L). Comparison of ephrinB2 probe and Flkl probe staining shows that ephrinB2 was selectively lost in the endothelium (Fig. 5I,L versus 5G,J, arrows), and was still present in the non-vascular tissues (Fig. 5G versus I, arrowheads) of conditional knockout embryos. Flkl in situ hybridization signals confirmed the presence of endothelial cells in these samples (Fig. 5J-L).

We anticipated that the endothelial specific knockout of ephrinB2 might result in a rescue by mesenchymal ephrinB2 of the ACV phenotype seen conventional ephrinB2lacZllacZ homozygous mutants. To our surprise, ephrinB2lacZlloxP;Tie2$\mathrm{Cre}^{+}$embryos at E9.5 show a failure of ACV assembly and remodeling (compare Fig. 5M with $\mathrm{O}$, arrows). This defect was indistinguishable from that seen in ephrinB2lacZllacZ homozygotes (compare Fig. 5N with O, arrows). To understand how the loss of endothelial ephrinB2 could affect the development of venous vessels apparently not in direct contact with ephrinB2-expressing arteries, we collected ephrinB2lacZ/+ embryos at the 12-13 somite stage (E8.5), a timepoint at which the $\mathrm{ACV}$ is in the process of forming, and 24 hours before the mutant phenotype is clearly visible in the ACV. The embryos were stained with anti-PECAM1, and anti- $\beta$-gal to detect the 
ephrinB2-lacZ expression. As expected (Wang et al., 1998), the dorsal aorta was positive for $\beta$-gal (Fig. 5P-R, red channel, arrows), as was the surrounding mesenchyme (Fig. 5P-R, red channel, black arrowheads). We observed numerous small branches emanating from the dorsal aorta (Fig. 5P-R, white arrowheads), extending to the forming ACV (Fig. 5P-R, outlined by broken white lines). This reveals that there is a transient continuity between the developing ACV network and the fully formed dorsal aorta at early stages, and that most these vessels appear to be pruned by E9.5. This transient contact may represent the locus at which arterial ephrinB2 function is required for proper $\mathrm{ACV}$ morphogenesis. Thus, these data suggest that ephrinB2 expressed in arterial endothelial cells is required for proper angiogenesis of veins.

\section{Endothelial ephrinB2 is required for angiogenesis of arteries in the head}

Vascularization of the head results in a characteristic hierarchical branching pattern of large to small vessels, including morphogenesis of the internal carotid artery (ICA) (Coffin and Poole, 1988). In ephrinB2lacZllacZ homozygous mutant embryos, this network does not develop properly, resulting in a disorganized, often fused network of capillaries (Fig. 6N) (Adams et al., 1999; Wang et al., 1998). EphrinB2 is expressed in arterial endothelial cells of the head (Fig. 6A,B, red channel, arrows), as well as extensively in the mesenchyme and neuroepithelium of the developing brain (Fig. 6A,B, red channel, black and white arrowheads respectively) (Wang et al., 1998). Previous studies have indicted that ephrinB2
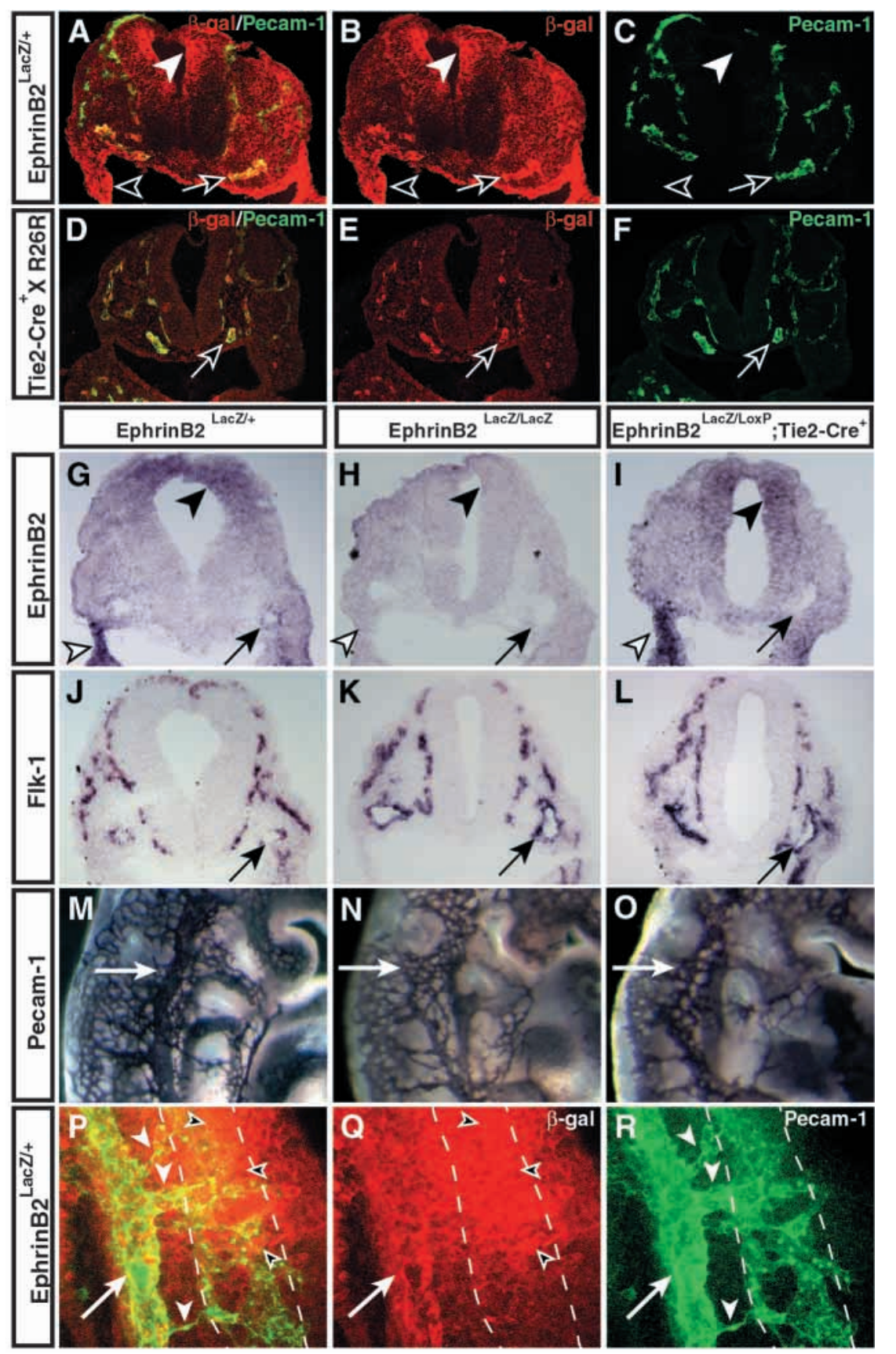

Fig. 5. Defective remodeling of the anterior cardinal vein $(\mathrm{ACV})$ of conditionally deleted ephrinB2 embryos. (A-C) EphrinB2 expression is widespread in the hindbrain. EphrinB2 $2^{\text {lac Z/+ }}$ mice at E9.5 were sectioned and stained for PECAM-1 (A and $C$, green channel) and $\beta$-gal ( $A$ and $B$, red channel). A merged image in A shows ephrinB2 expression in both arterial endothelium (yellow, arrows) and non-endothelial mesenchyme (red channel, black arrowheads) and neuroepithelium (red channel, white arrowheads). (D-F) Tie2-Cre activity is restricted to endothelial cells of the hindbrain. Embryos from a Tie2-Cre X Rosa-lacZ reporter cross at E9.5, sectioned and stained for PECAM-1 (D and F, green channel) and $\beta$-gal (D and $\mathrm{E}$, red channel) show complete overlap (arrows). A merged image is shown in (D). (G-L) EphrinB2 mRNA expression is lost specifically in the hindbrain vasculature of conditional knockout embryos. Sections through ephrinB2 lacZ/+ $(\mathrm{G}, \mathrm{J})$, ephrinB2lacZllacZ $(\mathrm{H}, \mathrm{K})$ and ephrinB2 $2^{\text {lacZlloxP }}$;Tie2$\mathrm{Cre}^{+}$(conditional knockout, I,L) hindbrain regions were hybridized with RNA in situ probes to ephrinB2 (G-I) and Flk1 (J-L), and show loss of ephrin $B 2$ in vessels of conditional knockout embryos (compare $\mathrm{G}$ and J with I and L, arrows). EphrinB2 mRNA is completely absent in the ephrinB2 $2^{\text {lacZllacZ }}$ conventional knockout $(\mathrm{H})$ but remains in the mesenchyme (white arrowheads) and neuroepithelium (black arrowheads) of conditional knockout embryos (compare G versus I). (M-O) Whole-mount PECAM-1 staining shows a failure of assembly of the ACV in conditional knockout embryos compared with ephrinB2 $2^{\text {lacZ/+ }}$ controls (compare $\mathrm{O}$ with $\mathrm{M}$, arrows). EphrinB2 $2^{\text {lacZllac }}$ embryos show an identical vascular phenotype (compare $\mathrm{O}$ with $\mathrm{N}$ ). Image in $\mathrm{O}$ is a close-up of embryo in Fig. 3C. (P-R) Vascular sprouts connect the ACV to the dorsal aorta at E8.5. Whole-mount staining for PECAM1 (P,R, green channel) and $\beta$ gal (P,Q, red channel) of ephrinB2 $2^{\text {lac } Z /+}$ mice show multiple vascular branches ( $\mathrm{P}$ and $\mathrm{R}$, white arrowheads) interconnecting the ACV primordium (P-R, outlined by broken white lines) and the ephrinB2 expressing dorsal aorta (arrows). A merged image in (P) shows mesenchymal ephrinB2 expression (red, black arrowheads) surrounding the immature ACV plexus (green channel, outlined by broken white lines). 
function is essential for angiogenesis of vessels in the head, but were unable to distinguish an autonomous requirement for ephrinB2 in the blood vessels, from a requirement in the neighboring head mesenchyme or neuroepithelium (Adams et al., 1999; Wang et al., 1998).

To examine Tie2-Cre activity in the head, we collected embryos at E9.5 from a Tie2-Cre X R26R lacZ reporter cross. Double-labeling with anti-PECAM1 and anti- $\beta$-gal (Fig. 6D-F, green and red channels, respectively) confirmed that lac $Z$ expression was only activated in the endothelium of the head (Fig. 6A versus 6D, arrows). To confirm that ephrinB2 expression was selectively lost in the vessels of ephrinB2 ${ }^{\text {lacZ/loxP }}$;ie2-Cre ${ }^{+}$mice, in situ hybridization with ephrinB2 and Flk1 RNA probes was performed on conventionally and conditionally knocked-out embryos and littermates. Comparison of ephrinB2 probe and $F l k 1$ probe staining indicated that ephrinB2 was selectively lost in the vasculature (Fig. 6G-I versus $6 \mathrm{~J}-\mathrm{L}$, arrows), and was still present in the non-vascular sites (Fig. 6G,I, arrowheads), of conditional knockout embryos. As expected, no ephrinB2 signal was present in ephrinB2 lacZ/lacZ embryos (Fig. 6H). Flk1 in situ hybridization signals in all samples confirmed that the loss of vascular ephrinB2 signals in mutant embryos was not due to a loss of endothelial cells in these samples (Fig. 6J-L, arrows).

In ephrinB2 $2^{\text {lacZlloxP }} ;$ Tie2-Cre ${ }^{+}$embryos the head vasculature fails to assemble correctly (Fig. $6 \mathrm{M}$ versus $6 \mathrm{O}$ ). The initial head plexus forms, but subsequently remains in a primitive state, a disorganized network of dilated capillaries. The ephrinB2 lacZ/lacZ homozygous mutant embryos exhibit an identical phenotype (compare Fig. 6N versus $6 \mathrm{O})$. Thus, in the conditional knockout of ephrinB2, the absence of endothelial ephrinB2 expression results in defective remodeling of the ICA, as well as the branches of the ACV, despite high mesenchymal and neuroepithelial ephrinB2 expression at this stage (Fig. 6A,B, red channel, arrowheads). These data indicate that endothelial ephrinB2 is required autonomously in arteries for proper arterial angiogenesis.

To determine whether the angiogenic phenotype of the conditional mutant reflects aberrant perivascular smooth muscle cell (SMC) recruitment or differentiation, we stained embryos at E9.5 with antibody to $\alpha$ smooth muscle actin ( $\alpha$ SMA). At this stage, however, there was not yet any $\alpha$ SMA expression in wildtype embryos in the smaller peripheral vessels of the ICA where phenotypic defects are observed in the mutant (data not shown). Therefore, it seems unlikely that a defect in SMC differentiation can account for the defective angiogenesis observed in the mutants. However,
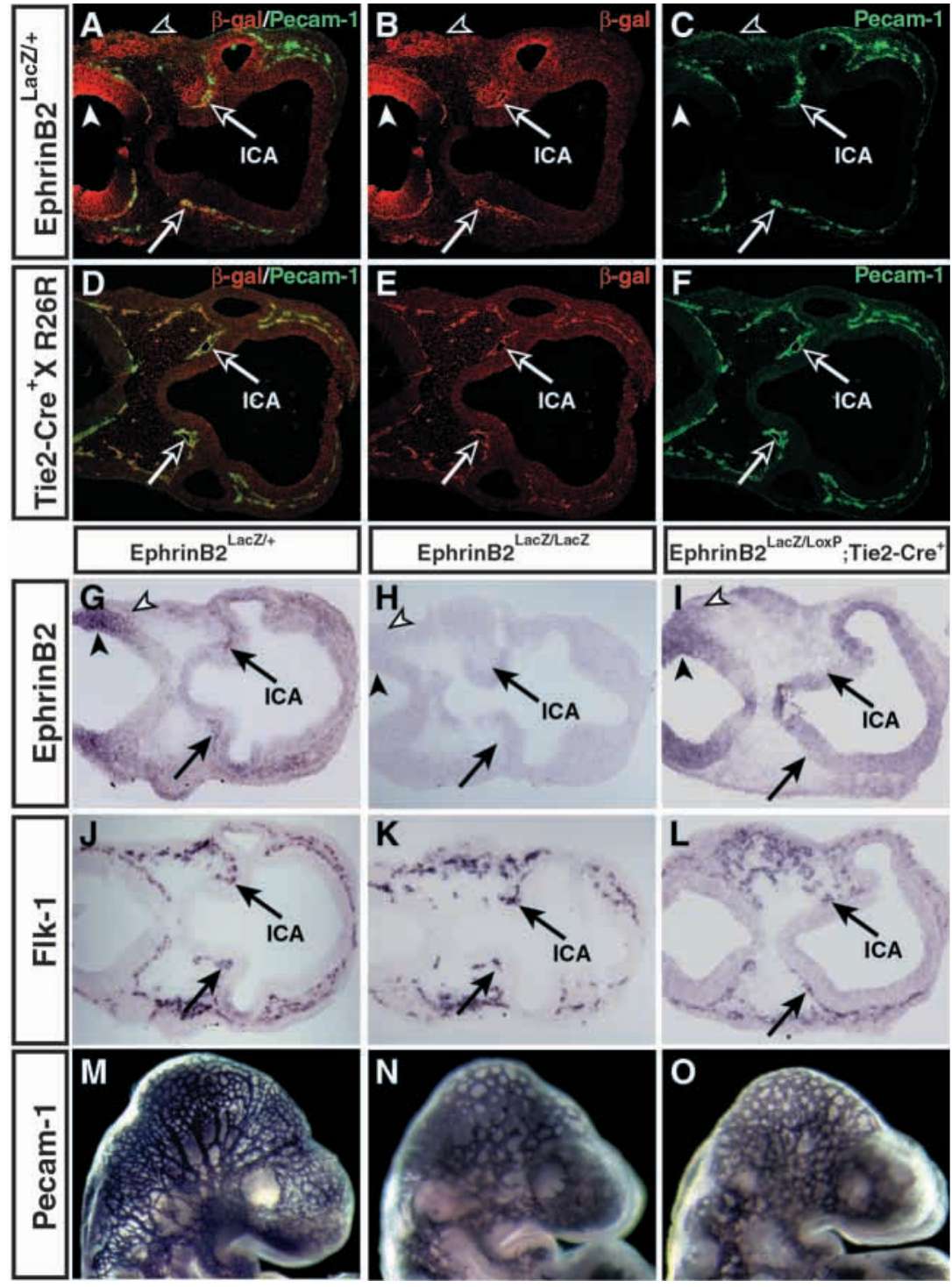

Fig. 6. Defective angiogenesis in the heads of conditionally deleted ephrinB2 embryos. (A-C) EphrinB2 expression is widespread in the head. EphrinB2 ${ }^{\text {lacZl+t }}$ mice at E9.5 were sectioned and stained for PECAM1 (A,C, green channel) and $\beta$-gal (A,B, red channel). A merged image in A shows ephrinB2 expression in both endothelial (yellow) and non-endothelial (red) mesenchymal (black arrowheads) and neuroepithelial (white arrowheads) tissues; ICA, internal carotid artery. (D-F) Tie2-

Cre activity in the head is restricted to endothelial cells. Embryos from a Tie2-Cre X Rosa-lacZ reporter cross at E9.5, sectioned and stained for PECAM-1 (D,F, green channel) and $\beta$-gal (D,E, red channel), show complete overlap. A merged image is shown in D. (G-L) EphrinB2 mRNA expression is lost specifically in the vessels of conditional knockout embryos. Sections through ephrinB2lacZ/+ $(\mathrm{G}, \mathrm{J})$,

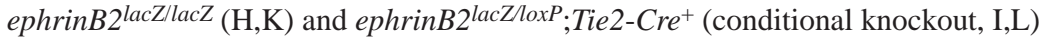
were hybridized with RNA in situ probes to ephrinB2 (G-I) and Flk1 (J-L), and show loss of ephrinB2 in vessels of conditional knockout embryos (compare $\mathrm{G}$ and $\mathrm{J}$ with I and L, arrows). ephrinB2 mRNA is completely lost in the ephrinB2lacZ/lacZ conventional knockout $(\mathrm{H})$, but remains in the mesenchyme (white arrowheads) and neuroepithelium (black arrowheads) of conditional knockout embryos (compare $\mathrm{G}$ with I). (M-O) Whole-mount PECAM1 staining shows arrested vascular remodeling in the heads of conditional ephrinB2 knockouts compared with littermate controls (compare $\mathrm{O}$ with $\mathrm{M}$ ). ephrinB2 $2^{\text {lac } Z \text { /lac } Z}$ heads show an identical vascular phenotype (compare $\mathrm{O}$ with $\mathrm{N}$ ). Images in $\mathrm{M}, \mathrm{O}$ are close-ups of embryos in Fig. 3F,C, respectively. 
it is possible that earlier markers of undifferentiated pericytes might reveal such a defect.

\section{Endothelial ephrinB2 is required for angiogenesis of intersomitic vessels}

The embryonic trunk is initially vascularized by a series of intersomitic vessels (ISVs) that arise from branches of the dorsal aorta (DA) and posterior cardinal veins. These vessels grow between adjacent somites to form a simple interconnected network dorsally around E8.75. Through extensive angiogenesis, this primitive structure elaborates an intricate network of small capillaries (Fig. 7M), some of which eventually invade the developing neural tube and flanking somites (Drake and Fleming, 2000; Coffin and Poole, 1988).

EphrinB2 is expressed in the arterial branches of the intersomitic vessels (Fig. 7AC, red channel, arrows) (Gerety et al., 1999) as well as in the caudal region of adjacent developing somites (Fig. 7A-C, red channel, arrowheads) (Adams et al., 1999; Gerety et al., 1999; Durbin et al., 1998; Wang et al., 1998; Wang and Anderson, 1997). ephrinB2 homozygous mutants fail to undergo angiogenic remodeling of the intersomitic vasculature (Fig. 7N) (Adams et al., 1999; Gerety et al., 1999). A similar phenotype is seen in mutants that lack EphB4, which is specifically expressed in ISVs and not in somitic mesenchyme (Gerety et al., 1999). Somitic ephrinB2 has also been implicated in ISV guidance in mouse and Хenopus (Helbling et al., 2000; Adams et al., 1999), although the penetrance of this phenotype appears variable in mice (Gerety et al., 1999).

To confirm that Cre activity is restricted to ISVs in the trunk, we examined embryos from a Tie2-Cre X R26R lacZ reporter intercross. Double-staining of such embryos for PECAM1 and $\beta$-gal confirmed that the $l a c Z$ reporter was specifically activated in the vessels (Fig. 7D-F, arrows), and not in the somites or other surrounding tissues (compare Fig. 7A with 7D). These data suggested that ephrinB2 expression should be selectively eliminated in the ISVs of ephrinB2 $2^{\text {lacZ/loxP }}$;ie $2-C r e^{+}$mice. To confirm this, in situ hybridization with ephrinB2 and Flk1 RNA probes was performed. Consistent with the Tie2-Cre X reporter data (Fig. 7D-F), these experiments indicated that in the conditional knockout, ephrinB2 is selectively lost in the vasculature (Fig. 7G-I versus J-L, insets, arrows, ' $\mathrm{V}$ '), but is still present in somites (Fig. 7G-I, arrowheads, and insets, 'S'). Endothelial cells are still present, however, as revealed by $F l k 1$ probe signals in all genotypes (Fig. 7J-L, arrows, and insets,

' $\mathrm{V}$ '). Complete loss of ephrinB2 in situ signal in the ephrinB2 conventional knockout confirmed the specificity of the riboprobes used (Fig. 7H).

Endothelial-specific ephrinB2 knockout embryos $\left(\right.$ ephrinB2 $2^{\text {lacZ/loxP }}$;ie2-Cre $\left.{ }^{+}\right)$show an arrest in intersomitic
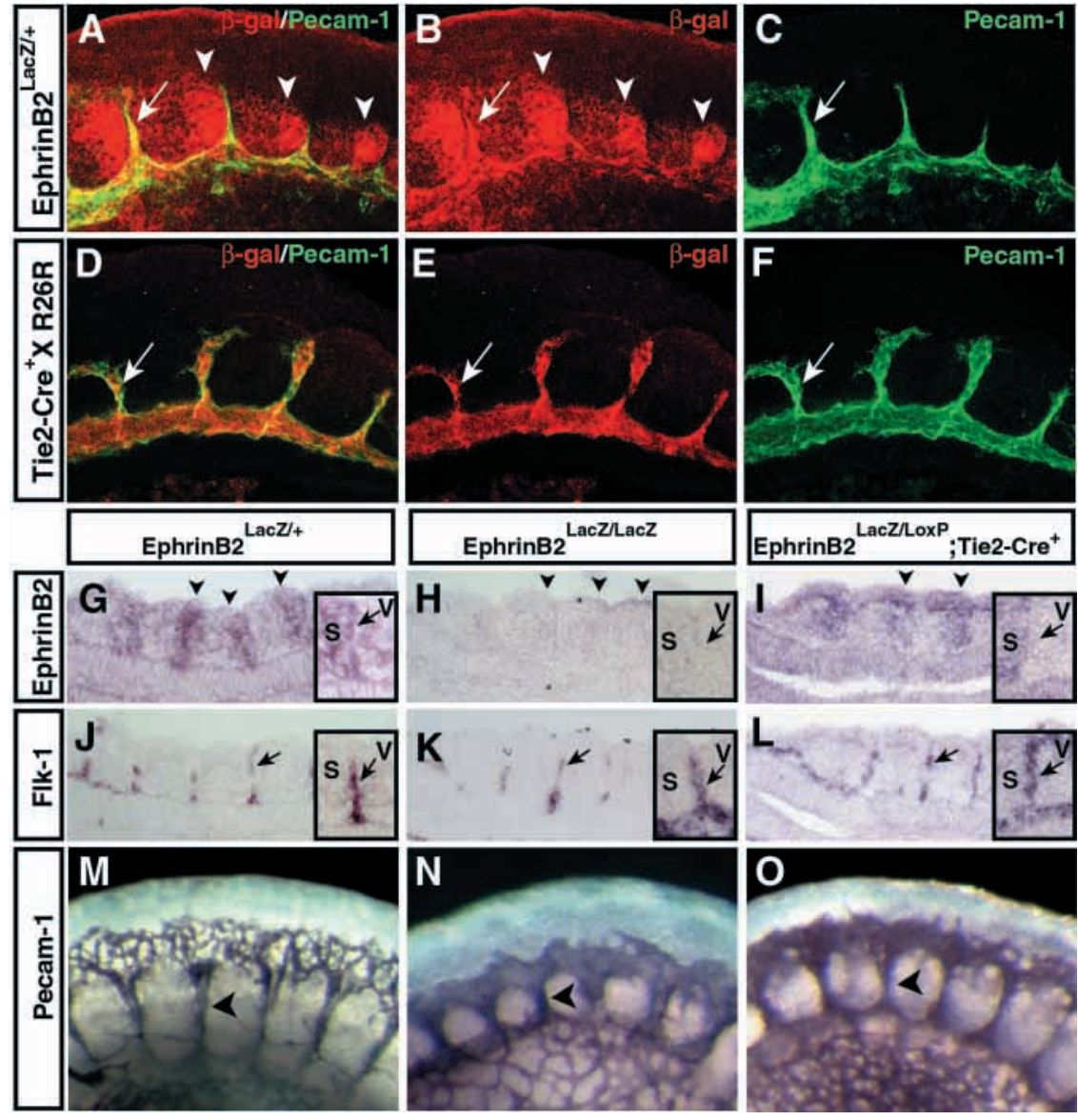

Fig. 7. Angiogenic arrest of the intersomitic vasculature in conditional ephrinB2 knockout embryos. (A-C) EphrinB2 expression is present in vascular and non-vascular trunk tissues. EphrinB2 $2^{\text {lacZ/+ }}$ mice at E8.5 were stained in whole-mount for PECAM1 $(\mathrm{A}, \mathrm{C}$, green channel) and $\beta$-gal $(\mathrm{A}, \mathrm{B}, \mathrm{red}$ channel). The dorsal aorta and its intersomitic sprouts (A-C, arrows) express ephrinB2-lacZ (red channel), as does the caudal half of each somite (A,B arrowheads). (D-F) Tie2-Cre activity is restricted to endothelial cells in the trunk. Whole-mount staining for PECAM1 (D,F, green channel) and $\beta$-gal (D,E, red channel) of E8.5 progeny of a Tie2-Cre X R26R lacZ reporter cross shows that $\beta$-gal expression, reflecting Tie2-Cre activity (E), is restricted to endothelial cells of the dorsal aorta and intersomitic vessels (D-F, arrows), as seen in merged image (D, yellow).

(G-L) EphrinB2 mRNA is still expressed in the somites of the conditional ephrinB2 knockout, as revealed by in situ hybridization with ephrinB2 (G-I) and Flk1 (J-L) RNA probes in E9 ephrinB2 $2^{\text {lacZ/+ }}$ control $(\mathrm{G}, \mathrm{J})$, ephrinB2 $2^{\text {lacZllacZ }}$ mutant $(\mathrm{H}, \mathrm{K})$ and

conditional ephrinB2 knockout (I,L) embryos. Somite expression of ephrinB2 in caudal half of somites (G-I, arrowheads) is completely lost in conventional knockout $(\mathrm{H})$ but is still present in the vessel-specific knockout (I), compared with control embryos (G). Insets in G-L confirm ephrinB2 expression in ISVs of ephrinB2lacZ/+ control embryos ( $\mathrm{G}$ versus $\mathrm{J}$, arrows), and its absence from these vessels in conventional ( $\mathrm{H}$ versus $\mathrm{K}$, arrows) and conditional mutants (I versus L, arrows); S, somite; V, vessel. (M-O) Absence of intersomitic vessel remodeling at E9.5 is revealed by whole-mount staining for PECAM1 in control ephrinB2 $2^{\text {lacZ/+ }}(\mathrm{M})$, ephrinB2 ${ }^{\text {lacZllacZ }}(\mathrm{N})$ and conditional knockout $(\mathrm{O})$ embryos. The ISV network is fused dorsally in both conventional $(\mathrm{N})$ and conditional $(\mathrm{O})$ ephrinB2 mutants, when compared with the elaborated network in control embryos (compare $\mathrm{N}$ and $\mathrm{O}$ with $\mathrm{M}$ ). ISV guidance appears normal in both conventional and conditional mutant embryos (M-O, arrowheads). Images in M,N are close-ups of embryos in Fig. 3F,B, respectively. 
vessel angiogenesis at the primary plexus stage (Fig. 7O, compare with $7 \mathrm{M}$ ). The vessels appear fused dorsally with little or no branching. This phenotype is identical to that of the ephrinB2 lacZllacZ mice (compare Fig. $7 \mathrm{~N}$ with $7 \mathrm{O}$ ) (Gerety et al., 1999). These data indicate that ephrinB2 is required in the intersomitic arteries for proper angiogenesis to occur. Thus, remodeling of ISVs requires ephrinB2-EphB4-mediated interactions between ISVs. Somite-derived ephrinB2 signal is apparently not sufficient to compensate for the requirement for ephrinB2 in these vessels.

We did not observe aberrant branching of ISVs into somitic mesenchyme in either our conventional or conditional ephrinB2 knockouts (Fig. 7N,O, arrowheads). This is in contrast to the phenotype described by Adams et al., in their conventional ephrinB2 knockout (Adams et al., 1999), as well as in a study employing mis-expression of dominant-negative Ephb4 alleles in Xenopus (Helbling et al., 2000), both of which describe aberrant ISV branches into adjacent somites. The difference in the penetrance of the ISV branching phenotype between the two conventional ephrinB2 mutations may reflect differences in genetic background (Gupta et al., 2001; Rohan et al., 2000). Consequently, we were unable to determine whether arterial ephrinB2 expression is required for proper intersomitic guidance of the ISVs. The question of whether ephrinB2 in somitic mesenchyme plays a role in guidance of ISVs will require a conditional knockout of the gene specifically in that tissue, on a genetic background that allows the penetrance of that phenotype.

\section{Endocardial ephrinB2 is required for heart development}

The endothelial lining of the early embryonic heart, the endocardium, is similar in many respects to the rest of the vasculature, in terms of gene expression, and cell behavior (reviewed by Gale and Yancopoulos, 1999; Brutsaert et al., 1998; Dumont et al., 1992; Dumont et al., 1995). Subsequent interactions with its specialized tissue environment leads to morphological changes, including heart looping and myocardial trabeculation, the formation of endothelial-cell lined projections from the supporting myocardium (Fishman and Chien, 1997). In the heart, ephrinB2 is expressed primarily in the endocardium (Fig. 8A-C, red channel, arrows) (Wang et al., 1998). EphrinB2 is also weakly expressed in myocardium or other support cells (Fig. 8A-C, red channel, arrowheads) (Wang et al., 1998). The heart phenotype in the conventional ephrinB2 knockout is an arrest of development resulting in no looping and little or no myocardial trabeculation, and frequent abnormal swelling of the heart (Adams et al., 1999; Gerety et al., 1999; Wang et al., 1998).

The Tie2-Cre deleter line we used excises in the heart (Fig. 8D-F, red channel) (Kisanuki et al., 2001), as early as E8.25 (Fig. 2E, arrows). No Tie2-Cre activity was seen outside of the endocardial lining (Fig. 8D-F, arrows, compare red and green channels for $\beta$-gal and PECAM1, respectively). Specific loss of ephrinB2 from the endocardium, and not from the myocardium, of conditional knockout embryos was confirmed by in situ hybridization (data not shown). In such conditionally deleted embryos (ephrinB2lacZ/loxP;Tie2-Cre ${ }^{+}$), we observed defective heart morphogenesis, including looping defects, swelling (Fig. 8I versus 8G) and severely reduced trabeculation (Fig. 8L versus J, arrowheads) compared with littermate controls. We observed the same phenotype in ephrinB2 lacZ/lacZ homozygous embryos (Fig. 8H,K versus 8I,L) (Adams et al., 1999; Gerety et al., 1999; Wang et al., 1998). Thus, endocardial ephrinB2 is essential for heart
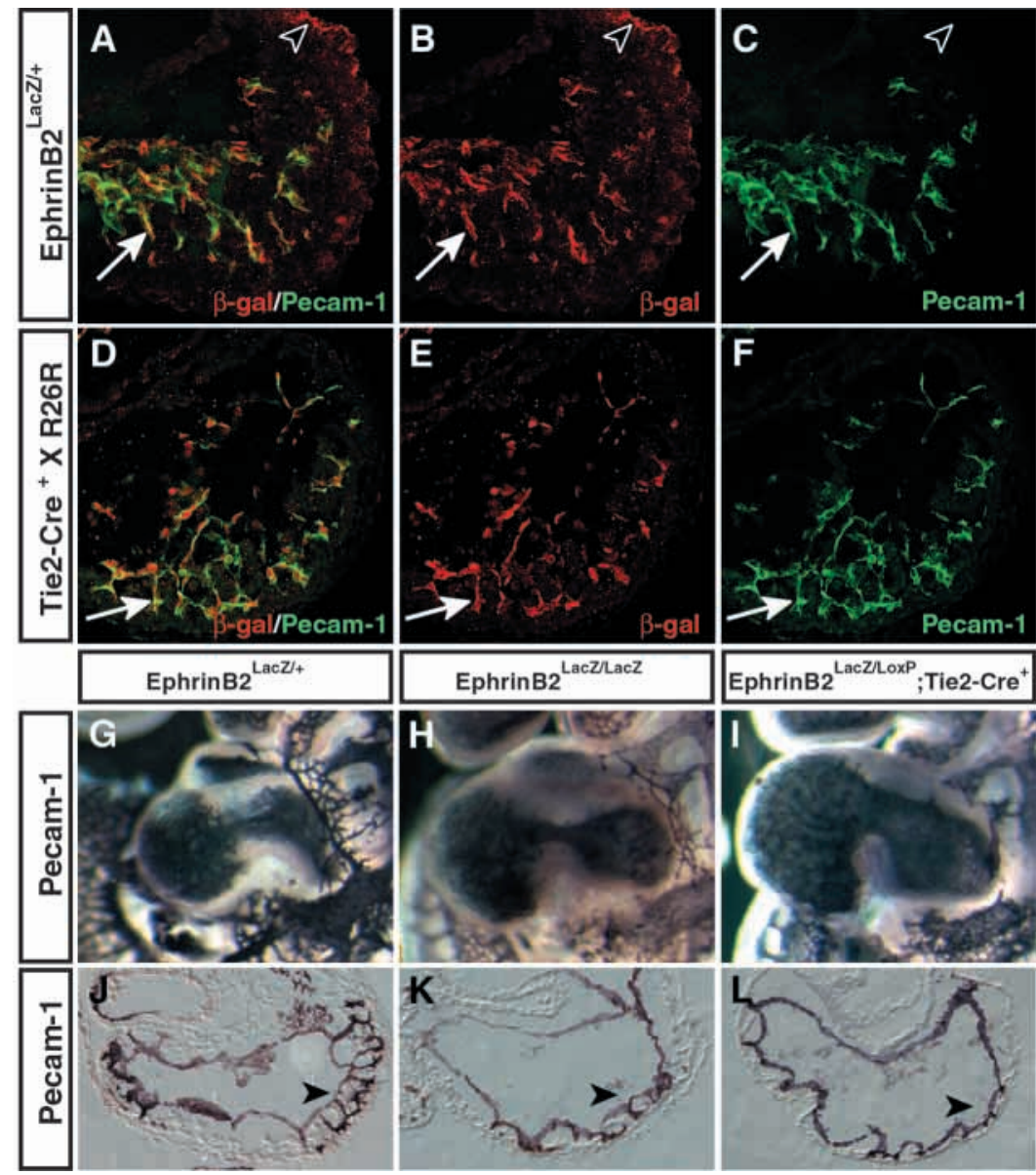

Fig. 8. Defective heart morphogenesis in both ephrinB2 conventional and conditional mutant embryos. (A-C) EphrinB2 is primarily expressed in the endocardial lining (arrows) of the heart, as revealed by sections of E9.5 ephrinB2 $2^{\text {lacZl+ }}$ embryos stained for PECAM1 (A,C, green channel) and $\beta$-gal (A,B, red channel). Some non-endocardial staining is seen (A-C, red channel not overlapping with green, arrowheads). (D-F) In the heart, restriction of Tie2-Cre activity to the endocardial lining is revealed by E9.5 sections of Tie2-Cre X R26R lac Z reporter cross embryos double-labeled for PECAM1 (D,F, green channel) and $\beta$-gal (D,E, red channel). A merged image (D) shows Tie2-Cre activity is found only in the PECAM1-positive endocardial lining (arrows). (G-I) EphrinB2 conventional and conditional embryos show swelling and defective looping of the heart compared with control ephrinB2 ${ }^{\text {lacZ/+ }}$ embryos (compare H and I with G), revealed by whole-mount anti-PECAM1 staining at E9.5. (J-L) PECAM1 stained sections of hearts reveal little or no myocardial trabeculation (arrowheads) in both the conditional and conventional mutants (compare L with $\mathrm{K}$ ) compared with control embryos (compare $\mathrm{K}$ and $\mathrm{L}$ with $\mathrm{J}$, arrowheads) at E9.5. 
morphogenesis. We observe heart beat and circulating erythrocytes in the aortic arches and dorsal aorta of some conditional ephrinB2 mutant embryos with vascular defects, suggesting that cardiac function is not completely lost at stages when peripheral angiogenic defects are visible.

\section{DISCUSSION}

Previous work established that ephrinB2 is specifically expressed in arteries and is required for embryonic angiogenesis (Adams et al., 1999; Wang et al., 1998). However, as ephrinB2 is expressed not only in endothelium, but also in mesenchymal tissues surrounding sites of angiogenesis, these studies could not distinguish between a vascular requirement and a mesenchymal requirement for the ephrinB2 signal. Understanding which tissues provide angiogenic ephrin signals influences the way we think about angiogenesis and the regulation of its morphogenetic processes (Yancopoulos et al., 2000). By knocking out ephrinB2 specifically in the developing vasculature, we have shown that endothelial and/or endocardial ephrinB2 expression is absolutely required for embryonic angiogenesis. The extensive mesenchymal expression of ephrinB2 around sites of active angiogenesis is not sufficient to compensate for the loss of endothelial ephrinB2.

\section{The functional requirement for ephrinB2 is intrinsic to the cardiovascular system}

Our data demonstrate that ephrinB2 is required in arterial endothelium for the remodeling of veins of the head, ACV and yolk sac, most probably by signaling through EphB4 receptor in these vessels. This ligand appears to be required cellautonomously in arteries as well, without which angiogenic remodeling of the ICA and vitelline artery is disrupted in the head and yolk sac, respectively. Although ephrinB2 is expressed at high levels in the somites flanking the developing ISVs, endothelial ephrinB2 is still required for the elaboration of a fine capillary network from the primitive intersomitic arteries and veins. These data, therefore, appear to reveal instances of forward, reverse and bi-directional signaling between arterial and venous vessels. Our results also demonstrate that even at sites of high mesenchymal ephrinB2, vascular expression is still absolutely essential, and argue that mesenchymal ephrinB2 alone is unable to support angiogenesis.

Our data do not exclude the possibility, however, that somitic ephrinB2 contributes to ISV growth and guidance. Adams et al., observe ISVs branching aberrantly into the somites in their ephrinB2 knockout, suggesting that ephrinB2 in the somites plays repulsive role, restricting the growth of ISVs to the intersomitic space (Adams et al., 1999). Our ephrinB2 knockout mice do not show a similar aberrant branching phenotype (Gerety et al., 1999). The reason for this difference is not clear. Strain differences may account for this discrepancy (Gupta et al., 2001; Rohan et al., 2000). Consistent with this, Adams et al. find ephrinB2 heterozygous offspring at half the expected proportions (Adams et al., 1999), while our ephrinB2 offspring are found at Mendelian ratios, suggestive of a reduced penetrance of the ephrinB2 mutant phenotype. Forced expression of ephrins or dominant-negative EphB4 receptor throughout the developing Xenopus embryo has a similar effect on ISV growth (Helbling et al., 2000). This ISV guidance model fits well with the repulsive guidance role ascribed to ephrinB2 signaling in neural crest migration and axon pathfinding in and around somitic tissue (Krull et al., 1997; Wang and Anderson, 1997). However, somite-specific deletion of ephrinB2 will be required to confirm that it exerts this ISV guidance function from non-vascular tissue.

\section{Necessity versus sufficiency: does mesenchymal ephrinB2 have a role in angiogenesis?}

Our loss-of-function results provide evidence of the necessity of endothelial ephrinB2 in angiogenesis, and indicate that mesenchymal ephrinB2 is insufficient to compensate for its loss from vessels. However, this does not address whether mesenchymal ephrinB2 expression is also required for angiogenesis. Given the extensive expression of ephrinB2 in the mesenchyme surrounding vessels in the head, trunk (Adams et al., 1999; Wang et al., 1998) and in smooth muscle (Gale et al., 2001; Shin et al., 2001), it is possible that this non-endothelial expression is required for angiogenesis in parallel with its requirement in the endothelium. If so, then the fact that the phenotypes of the conventional and endothelial-specific ephrinB2 knockouts are identical argues that such a parallel function for ephrinB2 in endothelial and mesenchymal cells must be non-redundant. Alternatively, the presence of ephrinB2 in the early embryonic mesenchyme may be irrelevant to angiogenesis, but instead reflects other potential roles, such as somite patterning (Durbin et al., 1998), neural crest migration (Adams et al., 2001; Krull et al., 1997; Wang and Anderson, 1997), hindbrain segmentation (Xu et al., 1995; Xu et al., 1996) and axon guidance (Frisen et al., 1998; Drescher et al., 1995). The direct test of a mesenchymal requirement for ephrinB2 in angiogenesis awaits the identification of mesenchymal promoter elements with which to generate mesenchyme-specific $\mathrm{Cre}$ deleter mice.

\section{ACV remodeling requires artery to vein ephrin signaling}

It has been hypothesized that the failure of $\mathrm{ACV}$ primordium to remodel into single-vessel structures in the ephrinB2 and Ephb4 mutants was the result of a loss of ephrinB2 stimulation from the adjacent mesenchyme (Adams et al., 1999; Gerety et al., 1999). An important factor in that interpretation was the lack of obvious $\mathrm{AV}$ interface between this venous structure and any arterial ephrinB2-expressing vessels. Based on this, we expected that in an endothelial-specific knockout of ephrinB2, we would see rescue of the ACV phenotype. Surprisingly, the ACV phenotype of our conditional knockout is identical to that of the conventional ephrinB2 knockout (Adams et al., 1999; Gerety et al., 1999). This suggests that an arterial source of ephrinB2 is required for ACV morphogenesis, such as the dorsal aorta. How could a physically remote tissue send a signal that is by nature membrane bound and requires cell-cell contact for transmission? Further analysis revealed transient endothelial continuity between the dorsal aorta and the developing ACV plexus at developmentally relevant stages during the assembly of these vessels. Based on the combination of conditional knockout phenotypes and the dorsal aorta-ACV contacts present in young embryos, we believe that the development of 
the ACV may require transient artery-vein interactions. This suggests that ACV development proceeds in a fashion similar to the rest of the vasculature, through $\mathrm{AV}$ interactions during which some vessels undergo pruning. Alternately, defective angiogenesis in the ACV might instead be due to insufficient blood flow resulting from aberrant cardiac development and function (see next section).

\section{Heart morphogenesis requires endocardial ephrinB2 expression}

During embryonic heart morphogenesis, essential interactions take place between endocardial cells (Gory-Faure et al., 1999), and between endocardial and myocardial cells (Meyer and Birchmeier, 1995) in a reciprocal manner (Carmeliet et al., 1996; Suri et al., 1996). These tissue relationships are essential for the remodeling of the primitive heart tube to the looped, highly trabeculated structure that emerges at E9.5 (Gale and Yancopoulos, 1999). Ephrin/Eph signaling has been implicated in these morphogenetic events both by expression and mutant phenotypes (reviewed by Adams and Klein, 2000). Because EphB4 is expressed in endocardial and not myocardial cells, the failure of myocardial trabeculation in the Ephb4 knockout demonstrates that Ephrin signals must be received by the endocardium (Gerety et al., 1999). Establishing the required source for the ephrinB2 signal is complicated again by the presence of this ligand in both the endocardium and the myocardium (Wang et al., 1998). Although the expression levels in the myocardium are much lower than in the endocardium, the possibility remained that the requisite Ephrin signal originates in the myocardium. We now show that endocardial ephrinB2 function is absolutely required for heart morphogenesis, and is not compensated for by myocardial ephrinB2. This indicates that ephrinB2-EphB4-mediated signaling between endocardial cells is required for this morphogenetic program to be executed.

The close temporal relationship between vascular and cardiac phenotypes in knockouts of most genes encoding angiogenic signaling molecules or their receptors (Gerety et al., 1999; Gory-Faure et al., 1999; Asahara et al., 1998; Carmeliet et al., 1996; Ferrara et al., 1996; Dickson et al., 1995; Sato et al., 1995; Dumont et al., 1994) invariably complicates phenotypic analysis and interpretation: a defect in peripheral angiogenesis could be the result of defective cardiac development and aberrant blood flow; conversely, defective heart development could be due to an obstructed or disorganized vasculature. We do observe heartbeat and blood flow in some conditional ephrinB2 mutant embryos with vascular defects, arguing that the defective peripheral angiogenesis in such mutants is not simply due to a complete lack of blood flow. However, aberrant hemodynamics could still contribute to the peripheral angiogenic defects seen in mutant embryos. Resolution of this issue awaits the development of appropriate Cre deleter transgenic mouse lines to temporally bypass the early cardiac requirement for ephrinB2 function, or alternatively identification of endothelial- or endocardial-specific promoter elements (Fishman, 1997), for loss-of-function or rescue experiments, respectively.

\section{EphrinB1 does not compensate for loss of endothelial ephrinB2}

EphrinB1 is co-expressed with ephrinB2 in arteries (Adams et al., 1999), but cannot compensate for the loss of ephrinB2 in a conventional knockout (Adams et al., 1999; Wang et al., 1998). The perivascular expression of these ligands, however, does not fully overlap (Wang and Anderson, 1997). Previously, therefore, one could have argued that the failure of ephrinB1 to compensate for ephrinB2 in the conventional knockout might reflect a requirement for ephrinB2 function in tissues where ephrinB1 is not expressed. However, the present data indicate that ephrinB1 cannot compensate for ephrinB2 within the cardiovascular system. This failure may reflect crucial differences in expression levels between the two ligands (Stein et al., 1998), or alternatively structural differences that create different functional properties. For example, ephrinB2 is the only ligand that can bind efficiently to EphB4 (Sakano et al., 1996; Brambilla et al., 1995). Although veins express other EphB receptors that can interact with ephrinB1, only EphB4 is essential for angiogenesis (Adams et al., 1999; Gerety et al., 1999). Finally, differences in expression patterns within the cardiovascular system could explain the inability of ephrinB1 to compensate for ephrinB2: although ephrinB2 is expressed only in arterial vessels (Adams et al., 1999; Wang et al., 1998), ephrinB1 is expressed in all vessels (Adams et al., 1999). The arterial restriction of ephrinB2 may therefore be an important aspect of its role in angiogenesis. Gene swapping experiments should reveal whether differences in the expression or activity of ephrinB1 and ephrinB2 account for their functional distinction.

\section{Reverse signaling by ephrinB2 in angiogenesis}

The interpretation of the vascular defects in the original ephrinB2 knockout was that reciprocal signaling between arterial ephrinB2 and venous EphB4 is required for the remodeling of both arteries and veins (Wang et al., 1998). An essential feature of this model is that upon engaging EphB4 receptors on veins, ephrinB2 functions as a receptor in arteries. This idea is supported by studies demonstrating that ephrinB cytoplasmic domains can undergo phosphorylation upon receptor binding (reviewed by Adams et al., 2001; Wilkinson, 2000; Mellitzer et al., 1999; Xu et al., 1999; Bruckner et al., 1997; Holland et al., 1996). Furthermore, a knockout of the ephrinB2 intracellular domain shows that the cytoplasmic tail of ephrinB2 is required for vascular morphogenesis (Adams et al., 2001). These data, and the fact that the Ephb4 mutation causes arterial as well as venous defects, suggest a requirement for reciprocal signaling by Eph receptors to ephrinB2 in vascular remodeling. Our results take this one step further, showing that, in fact, this reverse signal must be received by arterial endothelial cells and/or endocardial cells for angiogenesis to occur. Taken together, these data reinforce the idea that bi-directional signaling between ephrinB2 and EphB4 in the cardiovascular system is essential for angiogenesis (Wang et al., 1998).

Recent publications have highlighted the fact that many ephrins and Eph receptors are expressed in and around the adult vasculature at sites of active angiogenesis such as woundhealing and tumor angiogenesis, both in mice (Gale et al., 2001; Shin et al., 2001) and humans (reviewed by Takai et al., 2001; Dodelet and Pasquale, 2000; Ogawa et al., 2000; Berclaz et al., 1996). These reports hint at potential roles for ephrins and Ephs in normal and pathological angiogenesis in the adult. Establishing whether the adult expression patterns of these 
ligands and receptors reflect functional roles in these angiogenic events will be an important step in determining the potential relevance of ephrin/Eph targeting drugs for pro- or anti-angiogenic therapies of cardiovascular disease and cancer, respectively. Our study has demonstrated the potential of conditional knockouts in understanding ephrin function and expression, and provides a useful mouse model system to further examine these issues in the adult.

We thank T. Sato for the generous gift of Tie2-Cre transgenic mice, Emma Dormand for assistance with in situ hybridization techniques, Shirley Pease and the staff of the Transgenic Animal Facility at Caltech for assistance with animal husbandry, Gabriele Mosconi for laboratory management, Joanna Yamada for technical support, and Gina Mancuso for administrative assistance. D. J. A. is an Investigator of the Howard Hughes Medical Institute. This work was supported by NIH grant \#HL-66221-02 and American Heart Association grant \#9950157N.

\section{REFERENCES}

Adams, R. H. and Klein, R. (2000). Eph receptors and ephrin ligands. essential mediators of vascular development. Trends Cardiovasc. Med. 10, 183-188.

Adams, R. H., Wilkinson, G. A., Weiss, C., Diella, F., Gale, N. W., Deutsch, U., Risau, W. and Klein, R. (1999). Roles of ephrinB ligands and EphB receptors in cardiovascular development: demarcation of arterial/ venous domains, vascular morphogenesis, and sprouting angiogenesis. Genes Dev. 13, 295-306.

Adams, R. H., Diella, F., Hennig, S., Helmbacher, F., Deutsch, U. and Klein, R. (2001). The cytoplasmic domain of the ligand ephrinB2 is required for vascular morphogenesis but not cranial neural crest migration. Cell 104, 57-69.

Asahara, T., Chen, D., Takahashi, T., Fujikawa, K., Kearney, M., Magner, M., Yancopoulos, G. D. and Isner, J. M. (1998). Tie2 receptor ligands, Angiopoietin-1 and Angiopoietin-2 modulate VEGF-induced postnatal neovascularization. Circ. Res. 83, 233-240.

Berclaz, G., Andres, A. C., Albrecht, D., Dreher, E., Ziemiecki, A., Gusterson, B. A. and Crompton, M. R. (1996). Expression of the receptor protein tyrosine kinase myk-1/htk in normal and malignant mammary epithelium. Biochem. Biophys. Res. Commun. 226, 869-875.

Birren, S. J., Lo, L. and Anderson, D. J. (1993). Sympathetic neuroblasts undergo a developmental switch in trophic dependence. Development 119, 597-610.

Brambilla, R., Schnapp, A., Casagranda, F., Labrador, J. P., Bergemann, A. D., Flanagan, J. G., Pasquale, E. B. and Klein, R. (1995). Membranebound LERK2 ligand can signal through three different Eph- related receptor tyrosine kinases. EMBO J. 14, 3116-3126.

Breier, G., Breviario, F., Caveda, L., Berthier, R., Schnurch, H., Gotsch, U., Vestweber, D., Risau, W. and Dejana, E. (1996). Molecular cloning and expression of murine vascular endothelial-cadherin in early stage development of cardiovascular system. Blood 87, 630-641.

Brooks, P. C., Clark, R. A. F. and Cheresh, D. A. (1994). Requirement of vascular integrin $\alpha_{v} \beta_{3}$ for angiogenesis. Science 264, 569-571.

Bruckner, K., Pasquale, E. B. and Klein, R. (1997). Tyrosine phosphorylation of transmembrane ligands for Eph receptors. Science 275, 1640-1643.

Brutsaert, D. L., Fransen, P., Andries, L. J., De Keulenaer, G. W. and Sys, S. U. (1998). Cardiac endothelium and myocardial function. Cardiovasc Res. 38, 281-290.

Carmeliet, P., Ferreira, V., Breier, G., Pollefeyt, S., Kieckens, L., Gertsenstein, M., Fahrig, M., Vandenhoeck, A., Harpal, K., Eberhardt, C. et al. (1996). Abnormal blood vessel development and lethality in embryos lacking a single VEGF allele. Nature 380, 435-439.

Coffin, J. D. and Poole, T. J. (1988). Embryonic vascular development: immunohistochemical identification of the origin and subsequent morphogenesis of the major vessel primordia in quail embryos. Development 102, 735-748.

Daniel, T. O., Stein, E., Cerretti, D. P., St John, P. L., Robert, B. and
Abrahamson, D. R. (1996). ELK and LERK-2 in developing kidney and microvascular endothelial assembly. Kidney Int. 50, S73-S81.

Davis, S., Aldrich, T. H., Jones, P. F., Acheson, A., Compton, D. L., Jain, V., Ryan, T. E., Bruno, J., Radziejewski, C., Maisonpierre, P. C. et al. (1996). Isolation of Angiopoietin-1, a ligand for the TIE2 receptor, by secretion-trap expression cloning. Cell 87, 1161-1169.

Dickson, M. C., Martin, J. S., Cousins, F. M., Kulkarni, A. B., Karlsson, S. and Akhurst, R. J. (1995). Defective haematopoiesis and vasculogenesis in transforming growth factor-beta 1 knock out mice. Development 121, $1845-1854$

Dodelet, V. C. and Pasquale, E. B. (2000). Eph receptors and ephrin ligands: embryogenesis to tumorigenesis. Oncogene 19, 5614-5619.

Drake, C. J. and Fleming, P. A. (2000). Vasculogenesis in the day 6.5 to 9.5 mouse embryo. Blood 95, 1671-1679.

Drescher, U., Kremoser, C., Handwerker, C., Loschinger, J., Noda, M. and Bonhoeffer, F. (1995). In vitro guidance of retinal ganglion cell axons by RAGS, a $25 \mathrm{kDa}$ tectal protein related to ligands for Eph receptor tyrosine kinases. Cell 82, 359-370.

Dumont, D. J., Yamaguchi, T. P., Conlon, R. A., Rossant, J. and Breitman, M. L. (1992). Tek, novel tyrosine kinase gene located on mouse chromosome 4, is expressed in endothelial cells and their presumptive precursors. Oncogene 7, 1471-1480.

Dumont, D. J., Gradwohl, G., Fong, G.-H., Puri, M. C., Gerstenstein, M., Auerbach, A. and Breitman, M. L. (1994). Dominant-negative and targeted null mutations in the endothelial receptor tyrosine kinase, tek, reveal a critical role in vasculogenesis of the embryo. Genes Dev. 8, 18971909.

Dumont, D. J., Fong, G.-H., Puri, M. C., Gradwohl, G., Alitalo, K. and Breitman, M. L. (1995). Vascularization of the mouse embryo:a study of flk-1, tek, tie, and vascular endothelial growth factor expression during development. Dev. Dyn. 203, 80-92.

Durbin, L., Brennan, C., Shiomi, K., Cooke, J., Barrios, A., Shanmugalingam, S., Guthrie, B., Lindberg, R. and Holder, N. (1998). Eph signaling is required for segmentation and differentiation of the somites. Genes Dev. 12, 3096-3109.

Ferrara, N., Carver-Moore, K., Chen, H., Dowd, M., Lu, L., O'Shea, K. S., Powell-Braxton, L., Hillan, K. J. and Moore, M. W. (1996). Heterozygous embryonic lethality induced by targeted inactivation of the VEGF gene. Nature 380, 439-442.

Fishman, G. I. (1997). Timing is everything in life - conditional transgene expression in the cardiovascular system. Circ. Res. 82, 837-844.

Fishman, M. C. and Chien, K. R. (1997). Fashioning the vertebrate heart: earliest embryonic decisions. Development 124, 2099-2117.

Flamme, I., Frolich, T. and Risau, W. (1997). Molecular mechanisms of vasculogenesis and embryonic angiogenesis. J. Cell. Physiol. 173, 206-210.

Folkman, J. and D'Amore, P. A. (1996). Blood vessel formation: what is its molecular basis? Cell 87, 1153-1155.

Friedlander, M., Brooks, P. C., Schaffer, R. W., Kincaid, C. M., Varner, J. A. and Cheresh, D. A. (1995). Definition of two angiogenic pathways by distinct $\alpha_{\mathrm{v}}$ integrins. Science 270, 1500-1502.

Frisen, J., Yates, P. A., McLaughlin, T., Friedman, G. C., O'Leary, D. D. M. and Barbacid, M. (1998). Ephrin-A5 (AL1/RAGS) is essentail for proper retinal axon guidance and topographic mapping in the mammalian visual system. Neuron 20, 235-243.

Gale, N. W. and Yancopoulos, G. D. (1999). Growth factors acting via endothelial cell-specific receptor tyrosine kinases: VEGFs, Angiopoietins, and ephrins in vascular development. Genes Dev. 13, 1055-1066.

Gale, N. W., Baluk, P., Pan, L., Kwan, M., Holash, J., DeChiara, T. M., McDonald, D. M. and Yancopoulos, G. D. (2001). Ephrin-B2 selectively marks arterial vessels and neovascularization sites in the adult, with expression in both endothelial and smooth- muscle cells. Dev. Biol. 230, 151-160.

Gerety, S. S., Wang, H. U., Chen, Z. F. and Anderson, D. J. (1999). Symetrical mutant phenotypes of the receptor EphB4 and its specific transmembrane ligand ephrin-B2 in cardiovascular development. Mol. Cell 4, 403-414.

Gory-Faure, S., Prandini, M. H., Pointu, H., Roullot, V., Pignot-Paintrand, I., Vernet, M. and Huber, P. (1999). Role of vascular endothelial-cadherin in vascular morphogenesis. Development 126, 2093-2102.

Goumans, M. J., Zwijsen, A., van Rooijen, M. A., Huylebroeck, D., Roelen, B. A. and Mummery, C. L. (1999). Transforming growth factor-beta signalling in extraembryonic mesoderm is required for yolk sac vasculogenesis in mice. Development 126, 3473-3483.

Gupta, A. R., Dejneka, N. S., D'Amato, R. J., Yang, Z., Syed, N., Maguire, 
A. M. and Bennett, J. (2001). Strain-dependent anterior segment neovascularization following intravitreal gene transfer of basic fibroblast growth factor (bFGF). J. Gene Med. 3, 252-259.

Hanahan, D. (1997). Signaling vascular morphogenesis and maintenance. Science 277, 48-50.

Helbling, P. M., Saulnier, D. M. and Brandli, A. W. (2000). The receptor tyrosine kinase EphB4 and ephrin-B ligands restrict angiogenic growth of embryonic veins in Xenopus laevis. Development 127, 269-278.

Hellstrom, M., Kaln, M., Lindahl, P., Abramsson, A. and Betsholtz, C. (1999). Role of PDGF-B and PDGFR-beta in recruitment of vascular smooth muscle cells and pericytes during embryonic blood vesselformation in the mouse. Development 126, 3047-3055.

Hirschi, K. K., Rohovsky, S. A., Beck, L. H., Smith, S. R. and D'Amore, P. A. (1999). Endothelial cells modulate the proliferation of mural cell precursors via platelet-derived growth factor-BB and heterotypic cell contact. Circ. Res. 84, 298-305.

Holland, S. J., Gale, N. W., Mbamalu, G., Yancopoulos, G. D., Henkemeyer, M. and Pawson, T. (1996). Bidirectional signalling through the EPH-family receptor Nuk and its transmembrane ligands. Nature 383, 722-725.

Kisanuki, Y. Y., Hammer, R. E., Miyazaki, J., Williams, S. C., Richardson, J. A. and Yanagisawa, M. (2001). Tie2-Cre transgenic mice: a new model for endothelial cell-lineage analysis in vivo. Dev. Biol. 230, 230-242.

Kramer, R., Bucay, N., Kane, D. J., Martin, L. E., Tarpley, J. E. and Theill, L. E. (1996). Neuregulins with an Ig-like domain are essential for mouse myocardial and neuronal development. Proc. Natl. Acad. Sci. USA 93, 48334838.

Krebs, L. T., Xue, Y., Norton, C. R., Shutter, J. R., Maguire, M., Sundberg, J. P., Gallahan, D., Closson, V., Kitajewski, J., Callahan, R. et al. (2000). Notch signaling is essential for vascular morphogenesis in mice. Genes Dev. 14, 1343-1352.

Krull, C. E., Lansford, R., Gale, N. W., Collazo, A., Marcelle, C., Yancopoulos, G. D., Fraser, S. E. and Bronner-Fraser, M. (1997). Interactions of Eph-related receptors and ligands confer rostrocaudal pattern to trunk neural crest migration. Curr. Biol. 7, 571-580.

Lakso, M., Sauer, B., Mosinger, B., Jr., Lee, E. J., Manning, R. W., Yu, S. H., Mulder, K. L. and Westphal, H. (1992). Targeted oncogene activation by site-specific recombination in transgenic mice. Proc. Natl. Acad. Sci. USA 89, 6232-6236.

Ma, Q., Chen, Z., del Barco Barrantes, I., de la Pompa, J. L. and Anderson, D. J. (1998). neurogenin 1 is essential for the determination of neuronal precursors for proximal cranial sensory ganglia. Neuron 20, 469482.

Marchionni, M. A., Goodearl, A. D., Chen, M. S., BerminghamMcDonogh, O., Kirk, C., Hendricks, M., Danehy, F., Misumi, D., Sudhalter, J., Kobayashi, K. et al. (1993). Glial growth factors are alternatively spliced erbB2 ligands expressed in the nervous system. Nature 362, 312-318.

Mellitzer, G., Xu, Q. and Wilkinson, D. G. (1999). Eph receptors and ephrins restrict cell intermingling and communication. Nature 400, 77-81.

Meyer, D. and Birchmeier, C. (1995). Multiple essential functions of neuregulin in development. Nature 378, 386-390.

Nagy, A. (2000). Cre recombinase: the universal reagent for genome tailoring. Genesis 26, 99-109.

Ogawa, K., Pasqualini, R., Lindberg, R. A., Kain, R., Freeman, A. L. and Pasquale, E. B. (2000). The ephrin-A1 ligand and its receptor, EphA2, are expressed during tumor neovascularization. Oncogene 19, 6043-6052.

Oh, S. P., Seki, T., Goss, K. A., Imamura, T., Yi, Y., Donahoe, P. K., Li, L., Miyazono, K., ten Dijke, P., Kim, S. et al. (2000). Activin receptor-like kinase 1 modulates transforming growth factor- beta 1 signaling in the regulation of angiogenesis. Proc. Natl. Acad. Sci. USA 97, 2626-2631.

Orban, P. C., Chui, D. and Marth, J. D. (1992). Tissue- and site-specific DNA recombination in transgenic mice. Proc. Natl. Acad. Sci. USA 89, 6861-6865.

Oshima, M., Oshima, H. and Taketo, M. M. (1996). TGF-beta receptor type II deficiency results in defects of yolk sac hematopoiesis and vasculogenesis. Dev. Biol. 179, 297-302.

Patan, S. (2000). Vasculogenesis and angiogenesis as mechanisms of vascular network formation, growth and remodeling. J. Neuro-Oncol. 50, 1-15.

Pepper, M. S. (1997). Transforming growth factor-beta: vasculogenesis, angiogenesis, and vessel wall integrity. Cytokine Growth Factor Rev. 8, 2143.

Risau, W. and Flamme, I. (1995). Vasculogenesis. Annu. Rev. Cell Dev. Biol. 11, 73-91.
Rohan, R. M., Fernandez, A., Udagawa, T., Yuan, J. and D'Amato, R. J. (2000). Genetic heterogeneity of angiogenesis in mice. FASEB J. 14, 871876.

Sakano, S., Serizawa, R., Inada, T., Iwama, A., Itoh, A., Kato, C., Shimizu, Y., Shinkai, F., Shimizu, R., Kondo, S. et al. (1996). Characterization of a ligand for receptor protein-tyrosine kinase HTK expressed in immature hematopoietic cells. Oncogene 13, 813-822.

Sato, T. N., Tozawa, Y., Deutsch, U., Wolburg-Buchholz, K., Fujiwara, Y., Gendron-Maguire, M., Gridley, T., Wolburg, H., Risau, W. and Qin, Y. (1995). Distinct roles of the receptor tyrosine kinases Tie-1 and Tie-2 in blood vessel formation. Nature 376, 70-74.

Schlaeger, T. M., Qin, Y., Fujiwara, Y., Magram, J. and Sato, T. N. (1995). Vascular endothelial cell lineage-specific promoter in transgenic mice. Development 121, 1089-1098.

Schlaeger, T. M., Bartunkova, S., Lawitts, J. A., Teichmann, G., Risau, W., Deutsch, U. and Sato, T. N. (1997). Uniform vascular-endothelial-cellspecific gene expression in both embryonic and adult transgenic mice. Proc. Natl. Acad. Sci. USA 94, 3058-3063.

Schor, A. M., Canfield, A. E., Sutton, A. B., Arciniegas, E. and Allen, T. D. (1995). Pericyte differentiation. Clin. Orthop. 313, 81-91.

Shin, D., Garcia-Cardena, G., Hayashi, S., Gerety, S., Asahara, T., Stavrakis, G., Isner, J., Folkman, J., Gimbrone, M. A., Jr and Anderson, D. J. (2001). Expression of ephrinB2 identifies a stable genetic difference between arterial and venous vascular smooth muscle as well as endothelial cells, and marks subsets of microvessels at sites of adult neovascularization. Dev. Biol. 230, 139-150.

Shutter, J. R., Scully, S., Fan, W., Richards, W. G., Kitajewski, J., Deblandre, G. A., Kintner, C. R. and Stark, K. L. (2000). D114, a novel Notch ligand expressed in arterial endothelium. Genes Dev. 14, 1313-1318.

Soriano, P. (1999). Generalized lacZ expression with the ROSA26 Cre reporter strain. Nat. Genet. 21, 70-71.

Stein, E., Cerretti, D. P. and Daniel, T. O. (1996). Ligand activation of ELK receptor tyrosine kinase promotes its association with Grb10 and Grb2 in vascular endothelial cells. J. Biol. Chem. 271, 23588-23593.

Stein, E., Lane, A. A., Cerretti, D. P., Schoecklmann, H. O., Schroff, A. D., van Etten, R. L. and Daniel, T. O. (1998). Eph receptors discriminate specific ligand oligomers to determine alternative signaling complexes, attachment, and assembly responses. Genes Dev. 12, 667-678.

Suri, C., Jones, P. F., Patan, S., Bartunkova, S., Maisonpierre, P. C., Davis, S., Sato, T. N. and Yancopoulos, G. D. (1996). Requisite role of Angiopoietin-1, a ligand for the TIE2 receptor, during embryonic angiogenesis. Cell 87, 1171-1180.

Takai, N., Miyazaki, T., Fujisawa, K., Nasu, K. and Miyakawa, I. (2001). Expression of receptor tyrosine kinase EphB4 and its ligand ephrin-B2 is associated with malignant potential in endometrial cancer. Oncol. Rep. 8, 567-573.

Tybulewicz, V. L., Crawford, C. E., Jackson, P. K., Bronson, R. T. and Mulligan, R. C. (1991). Neonatal lethality and lymphopenia in mice with a homozygous disruption of the c-abl proto-oncogene. Cell $\mathbf{6 5}, 1153$ 1163.

Wang, H. U. and Anderson, D. J. (1997). Eph family transmembrane ligands can mediate repulsive guidance of trunk neural crest migration and motor axon outgrowth. Neuron 18, 383-396.

Wang, H. U., Chen, Z. F. and Anderson, D. J. (1998). Molecular distinction and angiogenic interaction between embryonic arteries and veins revealed by ephrin-B2 and its receptor Eph-B4. Cell 83, 741-753.

Wilkinson, D. G. (2000). Eph receptors and ephrins: regulators of guidance and assembly. Int. Rev. Cytol. 196, 177-244.

Xu, Q., Alldus, G., Holder, N. and Wilkinson, D. G. (1995). Expression of truncated Sek-1 receptor tyrosine kinase disrupts the segmental restriction of gene expression in the Xenopus and zebrafish hindbrain. Development 121, 4005-4016.

Xu, Q., Alldus, G., Macdonald, R., Wilkinson, D. G. and Holder, N. (1996). Function of the Eph-related kinase rtk1 in patterning of the zebrafish forebrain. Nature 381, 319-322.

Xu, Q., Mellitzer, G., Robinson, V. and Wilkinson, D. G. (1999). In vivo cell sorting in complementary segmental domains mediated by Eph receptors and ephrins. Nature 399, 267-271.

Yancopoulos, G. D., Davis, S., Gale, N. W., Rudge, J. S., Wiegand, S. J. and Holash, J. (2000). Vascular-specific growth factors and blood vessel formation. Nature 407, 242-248.

Zinyk, D. L., Mercer, E. H., Harris, E., Anderson, D. J. and Joyner, A. L. (1998). Fate mapping of the mouse midbrain-hindbrain constriction using a site- specific recombination system. Curr. Biol. 8, 665-668. 